\title{
Genetic parameters of important characteristics for the development of potato cultivars designed for industrial processing
}

\author{
T.A. da Silva ${ }^{1}$, I.R. Carvalho ${ }^{2}$, D.D. Wolter ${ }^{1}$, F.F. Cima ${ }^{1}$, \\ E.S. de Abreu ${ }^{1}$, E.A. Lenz ${ }^{1}$, F. Lautenchleger ${ }^{3}$, F.Q. Azevedo ${ }^{1}$ and \\ A.S. Pereira ${ }^{1}$ \\ ${ }^{1}$ Embrapa Clima Temperado, Pelotas, RS, Brasil \\ ${ }^{2}$ Universidade Regional do Noroeste do Estado do Rio Grande do Sul, Ijuí, \\ RS, Brasil \\ ${ }^{3}$ Universidade do Centro-Oeste (Unicentro), Guarapuava, PR, Brasil \\ Corresponding author: I.R. Carvalho \\ E-mail: carvalho.irc@gmail.com
}

Genet. Mol. Res. 19 (4): gmr18597

Received March 24, 2020

Accepted October 18, 2020

Published November 30, 2020

DOI http://dx.doi.org/10.4238/gmr18597

\begin{abstract}
Information on genetic parameters is essential to obtain rapid progress in the development of cultivars, which is of great interest to the potato processing industry in Brazil, as the consumption of processed potatoes has increased significantly in the last 10 years. Unfortunately the lack of raw material of quality limits its growth. Thus, the objective of this study was to estimate genetic parameters of characters of importance in the development of potato cultivars aimed at this agroindustry, in a hybrid population of 20 potato families in Embrapa's Potato Breeding Program. The experiment was carried out at Embrapa, Pelotas, RS, in two growing seasons. The design was randomized blocks with four replications; each repetition was composed of five genotypes of each family, and each plot was represented by five plants of each genotype. After harvesting, the tubers of each plot were evaluated for industrial quality, yield, external physiological defects and external appearance of tubers. The estimates of the variance components and genetic parameters (Restricted Maximum Likelihood) were obtained using the Harmonic Mean of the Relative Performance of the Genetic Values. There was an estimated high broad sense heritability for film
\end{abstract}


texture (TEX) and glucose (GLUC); and moderate for secondary growth (GRO), shape (SHA), dry mass (DM), general appearance (APP), percentage of commercial tubers mass (PCM), curvature (CUR), size uniformity (SIU), shape uniformity (SHU) ) and mean tuber mass (MTM). GLUC, SHA, TEX and APP showed superiority of the genotypic coefficient of variation $(\mathrm{CVg})$ in relation to the residual coefficient of variation $(\mathrm{CVe})$, for these characters. The highest CVg - CVe ratios were obtained for SIU, PCM, SHU, DM and GRO. In the light of this study, it is suggested that strong selection pressure can be applied to the characters GLUC, SHA, TEX and APP, and moderate selection pressure to SIU, PCM, SHU, DM, and GRO.

Key words: Solanum tuberosum; Heritability; Selection pressure; Prediction of genotypic values; Potato breeding; Industrial; Agronomic ideotype

\section{INTRODUCTION}

Demand for fast-food and ready-to-eat foods is a growing trend in the population, which is reflected in increased consumption of processed potatoes in the form of frozen prefried sticks (Nascimento, 2017), with a future prospect of global appreciation of this agroindustry (Prasannan, 2017). However, only a quarter of the raw material used for this purpose in Brazil is produced in the country (Pereira and Silva, 2019). This is mainly because the cultivars used in Brazil for this purpose were developed in temperate climate with long days, which hinders adaptation to Brazilian tropical and subtropical conditions, interfering with their productivity and quality (Bradshaw et al., 2006). Thus, the development of Brazilian materials is of fundamental importance for the growth and sustainability of this sector (Pereira and Silva, 2019).

Among the many characters to be considered in the selection process, it is important that genotypes aimed at this market have tubers with high dry matter content (20-24\%), aiming at good texture and industrial yield (Zorzella et al., 2003); and also low in reducing sugars (glucose and fructose) ( $\leq 1.2 \mathrm{mg} . \mathrm{g}^{-1}$ fresh mass) (Stark, 2003), aiming at light colors in frying (Dale and Bradshaw, 2003). Both characters must be preserved during storage, since the industry is supplied with freshly harvested tubers and stored material. In addition, the tubers must have an elongated shape, low susceptibility to physiological disorders, and high productivity, which is essential for the acceptance of a new cultivar (Pereira and Silva, 2019).

In addition, materials developed for growing in Brazil must be heat tolerant, since even during the winter harvest, the maximum average temperature is higher than the ideal temperature for growing potatoes (Birch et al., 2012; Rykaczewska, 2013). This, added to the estimates of global temperature increase (Hijmans, 2003), shows the need for efforts to mitigate the impact of heat on the crop. This stress, in addition to reducing productivity and increasing the occurrence of physiological disorders (Levy et al., 1991), acts by reducing the dry mass content of tubers (Menezes et al., 2001) and changing their performance during storage, which have early sprouting, an increase in sucrose and reducing sugars, and changes in resistance to sweetening induced by cold (Zommick et al., 2014). 
The potato's tetrasomic inheritance in conjunction with multialelism makes genetic studies and breeding of this crop complex, especially of quantitative traits (Pereira et al., 2016). Therefore, for the definition of effective selection strategies, avoiding superior genotypes to be discarded, it is very important to have information of the genetic parameters of the characters (Love, 1997). Heritability is one of the most important parameters for genetic improvement, as it expresses the reliability of the phenotypic value in predicting genetic value (Falconer, 1987). For potato, heritability in the broad sense is of greater importance, as the effects of dominance and epistasis are sustained in successive generations by clonal propagation (Howard, 1978). Selection of quality clones for industrial processing would be facilitated by information on the inheritance of the characters that compose it, and although several studies on heritability in both clone and family have been reported Salamoni et al. (2000), heritability estimates are unique, depend on the genetic diversity of the material tested and are strongly influenced by growing conditions (Bisognin et al., 2012). In addition, the existence of genotype-environment interaction may reduce the industrial quality character selection response (Hayes and Thill, 2003), and selection of clones based on evaluation in different production environments is required, however, most heritability and selection response studies for industrial processing quality traits are directed to distinct growing conditions from Brazil (Hayes and Thill, 2003; Bisognin et al., 2012). Given the above, the objective of this study was to estimate genetic parameters for yield traits, industrial quality, external appearance and external physiological defects in potato tubers in Brazilian grown cultivars.

\section{MATERIAL AND METHODS}

A hybrid potato population consisting of 20 families (lines) usually used by Embrapa's Breeding Program in the development of cultivars aimed at industrial processing was evaluated. They come from hybridizations between parents with complementary characteristics for processing (low glucose content, high dry mass content, elongated tuber shape) and genetically distant (Table 1). These parents (commercial cultivars and elite clones of Embrapa Clima Temperado) are part of Embrapa's active germplasm bank.Information on their characteristics and genetic origin can be accessed on the Alelo Vegetal portal (www.embrapa.br/alelo).

Table 1. List of potato families used in this study and their respective genealogies. Embrapa, Pelotas, 2020.

\begin{tabular}{llllll}
\hline Family & Parent $q$ & Parent $\delta$ & Family & Parent ${ }^{-}$ & Parent $\delta^{\wedge}$ \\
\hline 2 & BRS Ana & C1890-1-97 & 19 & C1750-15-95 & Asterix \\
5 & C2519-12-06 & $118-1$ & 20 & Markies & C1883-22-97 \\
7 & BRS Ana & IAC-Ibituaçu & 21 & BRSIPR Bel & Markies \\
8 & BRSIPR Bel & IAC-Ibituaçu & 25 & 118.1 & CL07-05 \\
11 & BRSIPR Bel & Ludmilla & 26 & BRSIPR Bel & Monalisa \\
12 & BRSIPR Bel & C1883-22-97 & 27 & F88-01-05 & Monalisa \\
13 & BRSIPR Bel & Amorosa & 34 & BRSIPR Bel & Voyager \\
16 & Baronesa & Asterix & 35 & Caesar & C2514-05-06 \\
17 & BRS Ana & Monalisa & 36 & BRSIPR Bel & Cupido \\
18 & BRSIPR Bel & Asterix & 37 & C1730-7-94 & Aracy \\
\hline
\end{tabular}


The trial was conducted in the experimental field of Embrapa Temperate Climate's Headquarters, in Pelotas, RS (latitude $31^{\circ} 42^{\prime} \mathrm{S}$, longitude $52^{\circ} 24^{\prime} \mathrm{W}$, altitude $40-50 \mathrm{~m}$ ), in two distinct growing periods. The first was carried out in the spring of 2017, because during this period the environmental conditions are more favorable for the expression of tuber quality characters (Müller et al., 2009) (Figure 1). And, the second growing period was performed in the summer of 2017/2018, when temperatures are higher (Embrapa, 2019), in order to select heat tolerant families (Temmerman et al., 2002) (Figure 1).
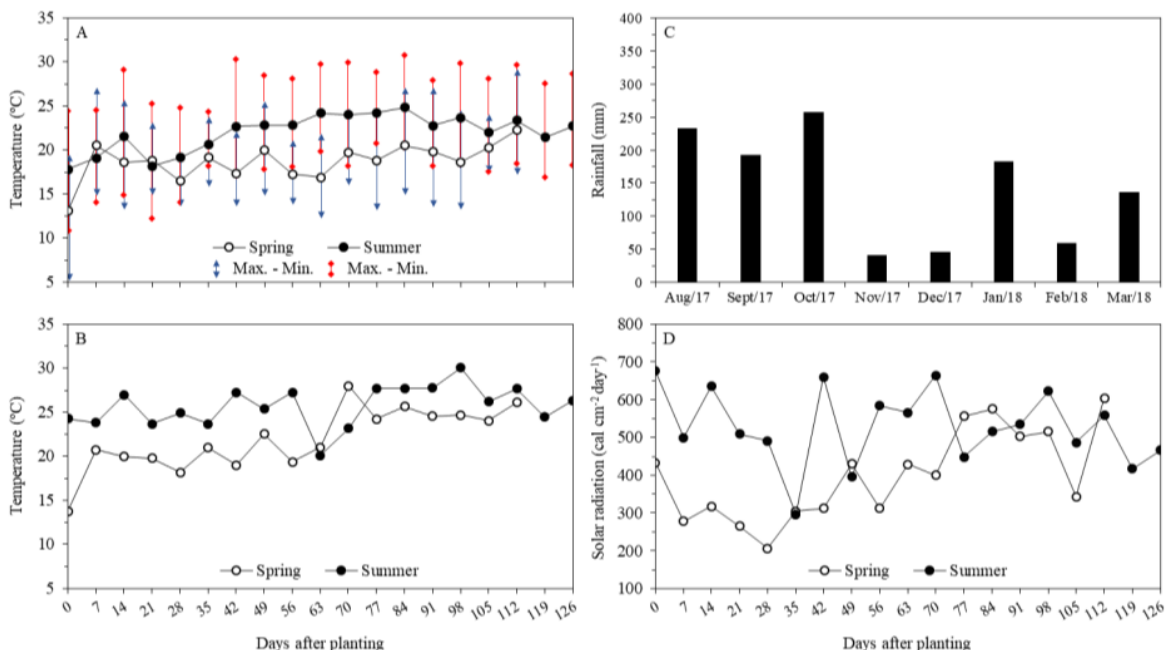

Figure 1. Weekly average air temperature (A), average soil temperature (B), rainfall (C) and incident solar radiation (D) during potato growing in spring 2017 and summer 2017/18 in Pelotas-RS. Embrapa, Pelotas, 2020.

Third-generation clonal seed tubers (tubers field-multiplied three times after seedling generation) were used, and at this stage there is a higher number of tubers by genotype, enabling industrial quality assessments, the tubers used in spring and summer harvests remained stored in cold chamber at temperatures of $3.5 \pm 0.5^{\circ} \mathrm{C}$ for eight and 11 months, respectively. The seed tubers of the control cultivars were type II (diameter between 40 and $50 \mathrm{~mm}$ ).

The experimental design was randomized blocks with four replications. Each repetition consisted of a random sample of five genotypes from each family, totaling 20 genotypes per family. As common treatments to all blocks, the cultivars Asterix, Atlantic, Baronesa, BRSIPR Bel, BRS Eliza and Epagri 361-Catucha were used. The plot was represented by five tubers spaced $0.40 \mathrm{~m}$ in the line and $0.75 \mathrm{~m}$ between lines. The crop and phytosanitary practices followed the recommended for the crop in the region, and the weather conditions were typical for the growing environments, however in the summer season there was a need for supplemental irrigation. In the spring season, the planting was carried out on $08 / 22 / 2017$, and in the summer season on 11/01/2017. The incidence of potato blight, one of the main diseases affecting the potato crop, caused by the oomycete Phytophthora infestans, belonging to the Pythiaceae family (Töfoli et al., 2016), in the final phase of the crop cycle in spring led to an early harvest of tubers. At 106 days after planting in spring and 122 days in summer, the tubers of each plot were harvested and yield, external 
physiological defects, sprouting, dry matter content, glucose content, and external appearance characters were evaluated.

The traits analyzed were: total tuber mass (TTM: kg.parcel ${ }^{-1}$ ), mass of commercial tubers (MCT: kg.parcel ${ }^{-1}$ ), mean tuber mass (obtained by dividing the total mass of the plot by the total number of tubers - MTM: g.tuber ${ }^{-1}$ ), percentage of the commercial tuber mass (obtained by dividing the mass of commercial tubers by the total mass of tubers, multiplied by 100 - PCM: \%), secondary growth (GRO: \%), greening (GRE: \%), cracking (CRA: \%), sprouting (SPR: \%) (Figure 2A, 2B, 2C and 2D, respectively), dry mass (DM: \%) (AOAC,1995), content of reducing sugars was quantified based on glucose (GLUC: $\mathrm{mg} \cdot \mathrm{g}^{-1}$ fresh mass) (Silva, 2019). To evaluate the external appearance characters of tubers, a ninepoint grading scale (Silva et al., 2014) was used for: film texture (TEX: Figure 2E), tuber shape uniformity (SHU), tuber size uniformity (SIU), tuber pointing (Figure 2F), tuber curvature (CUR), overall tuber appearance (APP) and tuber shape (SHA).
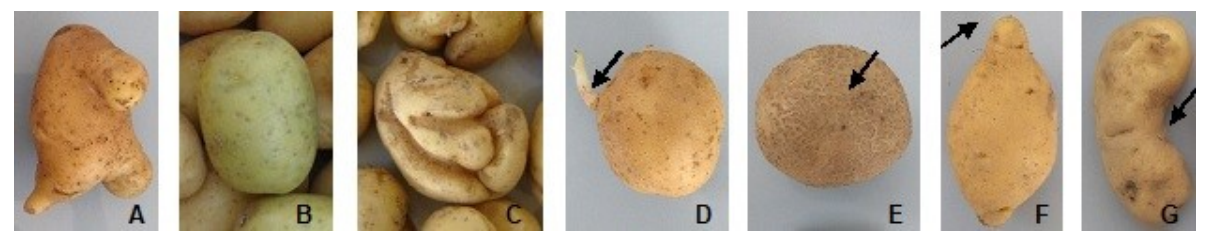

Figure 2. Characteristics of external physiological defects and external appearance of potato tubers. A: secondary growth; B: greening C: cracking; D: sprouting; E: film texture (rough); F: pointing (accented); G: curvature (sharp). Embrapa, Pelotas, 2020.

The data obtained were submitted to deviance analysis at $5 \%$ probability by the chisquare test $\left(\mathrm{X}^{2}\right)$. In order to verify the assumptions, the normality and homogeneity test of the residual variances was performed. Subsequently, estimates of variance components and genetic parameters (REML - Restricted Maximum Likelihood) were made using the method harmonic mean of the relative performance of genetic values, followed by the statistical model: $\mathrm{y}-\mathrm{Xr}+$ $\mathrm{Zg}+\mathrm{Wi}+\mathrm{e}$, where: $\mathrm{y}$ is the data vector, $\mathrm{r}$ is the effects of repeats (fixed), $\mathrm{g}$ is the genotypic effects (random), $i$ is the effects of genotype-environment interaction (random), and, e: are the residues (random). Genotypic variance $\left(\sigma_{\mathrm{G}}^{2}\right)$, variance of genotype-environment interaction $\left(\sigma_{\mathrm{INT}}^{2}\right)$, residual variance $\left(\sigma_{\mathrm{E}}^{2}\right)$, phenotypic variance $\left(\sigma_{\mathrm{P}}^{2}\right)$, broad sense heritability for total genotypic effects without interference from genotype-environment interaction $\left(\hat{\mathrm{H}}_{\mathrm{g}}{ }_{\mathrm{g}}\right)$, genotype mean heritability $\left(\hat{\mathrm{H}}^{2} \mathrm{mg}\right)$, accuracy for genotype selection ( $\left.\breve{\mathrm{r} g} \mathrm{~g}\right)$, coefficient for determining the effects of genotype-environment interaction $\left(\mathrm{C}^{2}{ }_{\mathrm{INT}}\right)$, genotypic correlation between environmental performance ( $\left.\mathrm{rg}_{\mathrm{loc}}\right)$, genotypic coefficient of variation $(\mathrm{CVg})$, residual coefficient of variation $(\mathrm{CVe})$ and the overall average were estimated. The Best Linear Unbiased Prediction was estimates were made to obtain the averaging components and select the best families, as well as to estimate the genetic value $(\mathrm{g})$, predicted genotypic value $(\mathrm{u}+\mathrm{g})$, mean predicted genotypic value $(\mathrm{u}+\mathrm{g}+\mathrm{gem})$, gain with selection (Gain) and new average with selection ( $\mathrm{N}$ Average). The analyses were performed with the aid of the statistical software Selegen (Resende, 2007).

\section{RESULTS}

The deviance analysis showed significant differences $(\mathrm{P} \leq 0.05)$ for the characters TTM, MCT, MTM, PCM, DM, GLUC, GRE, CRA, GRO, SPR, SHA, TEX, SHU, SIU, CUR and APP (Table 2). These results indicate that the variance components and genetic parameters (REML) 
estimated for the 20 potato families grown in the spring 2017 and summer 2017/2018 crops in the municipality of Pelotas, Rio Grande do Sul State (Table 2) are consistent and reliable. Based on the meteorological data from Embrapa's Temperate Climate Agrometeorology Laboratory (Embrapa, 2019), the average maximum temperature for spring growing was $24.2^{\circ} \mathrm{C}$; and for summer growing was $27.9^{\circ} \mathrm{C}$, which is higher than the ideal range for the growth of the plant shoot $\left(20.0\right.$ to $\left.25.0^{\circ} \mathrm{C}\right)$. Regarding the average soil temperature, in the two growing periods, spring $\left(21.9^{\circ} \mathrm{C}\right)$ and summer $\left(25.7^{\circ} \mathrm{C}\right)$, the temperature was higher than ideal for tuber formation $\left(15.0\right.$ to $\left.20.0{ }^{\circ} \mathrm{C}\right)$. Heat stress, in addition to reducing crop productivity and increasing the occurrence of physiological disorders, acts by reducing the dry matter content of tubers (Menezes et al., 2001) and changing the performance of tubers during storage, which have early sprouting, increased sucrose and reducing sugars, and change in resistance to cold-induced sweetening (Herman et al., 2016). Thus, the information contained in this study, obtained from Silva (2019), meets the demand for estimates of genetic parameters under heat stress, which is commonly found in potato growing regions in Brazil.

Table 2. Estimates of variance components and genetic parameters (REML) for 20 complementary potato families for industrial and genetically distant traits, evaluated in the third clonal generation, in spring 2017 and summer 2017/18 crops in Pelotas-RS. Embrapa, Pelotas, 2020.

\begin{tabular}{|c|c|c|c|c|c|c|c|c|}
\hline \multirow{2}{*}{ REML Variance Components ${ }^{1}$} & \multicolumn{8}{|c|}{ Characters $^{2}$} \\
\hline & TTM & MCT & MTM & PCM & DM & GLUC & GRE & CRA \\
\hline Deviance & 34.66 & 23.71 & 23.49 & 58.12 & 49.72 & 53.56 & 14.57 & 8.86 \\
\hline$\sigma_{G}^{2}$ & 0.06 & 0.03 & 26.22 & 87.94 & 1.41 & 0.01 & 0.10 & 1.05 \\
\hline$\sigma_{I N T}^{2}$ & 0.09 & 0.05 & 11.07 & 28.81 & 0.29 & 0.00 & 1.86 & 1.16 \\
\hline$\sigma_{E}^{2}$ & 0.25 & 0.16 & 83.37 & 136.42 & 2.35 & 0.01 & 3.89 & 6.06 \\
\hline$\sigma_{P}^{2}$ & 0.41 & 0.23 & 120.66 & 253.17 & 4.05 & 0.03 & 5.85 & 8.27 \\
\hline$\hat{H}_{g}^{2}$ & 0.16 & 0.11 & 0.22 & 0.35 & 0.35 & 0.47 & 0.02 & 0.13 \\
\hline$\hat{H}_{m g}^{2}$ & 0.46 & 0.37 & 0.62 & 0.74 & 0.76 & 0.84 & 0.06 & 0.43 \\
\hline$\check{R} g \check{g}$ & 0.68 & 0.61 & 0.79 & 0.86 & 0.87 & 0.92 & 0.24 & 0.65 \\
\hline$C_{I N T}^{2}$ & 0.22 & 0.21 & 0.09 & 0.11 & 0.07 & 0.06 & 0.32 & 0.14 \\
\hline$\check{r} g_{l o c}$ & 0.42 & 0.35 & 0.70 & 0.75 & 0.83 & 0.88 & 0.05 & 0.48 \\
\hline$C V g_{(\%)}$ & 13.33 & 18.67 & 11.61 & 26.41 & 5.86 & 51.97 & 11.72 & 35.22 \\
\hline $\mathrm{CVe}_{(\%)}$ & 26.44 & 45.94 & 20.71 & 32.89 & 7.57 & 51.70 & 74.13 & 84.51 \\
\hline \multirow{2}{*}{ Overall mean } & 1.91 & 0.86 & 44.09 & 35.51 & 20.23 & 0.21 & 2.66 & 2.91 \\
\hline & GRO & SPR & SHA & TEX & SHU & SIU & CUR & APP \\
\hline Deviance & 14.13 & 19.32 & 93.07 & 90.43 & 66.5 & 69.48 & 21.62 & 134.93 \\
\hline$\sigma_{G}^{2}$ & 7.22 & 1.88 & 99.33 & 0.31 & 0.29 & 0.28 & 0.14 & 0.88 \\
\hline$\sigma_{I N T}^{2}$ & 0.15 & 19.63 & 31.30 & 0.03 & 0.22 & 0.17 & 0.00 & 0.46 \\
\hline$\sigma_{E}^{2}$ & 14.49 & 27.91 & 93.17 & 0.28 & 0.47 & 0.39 & 0.47 & 0.52 \\
\hline$\sigma_{P}^{2}$ & 21.85 & 49.42 & 223.80 & 0.62 & 0.98 & 0.85 & 0.61 & 1.86 \\
\hline$\hat{H}_{g}^{2}$ & 0.33 & 0.04 & 0.44 & 0.50 & 0.29 & 0.33 & 0.23 & 0.48 \\
\hline$\hat{H}_{m g}^{2}$ & 0.79 & 0.09 & 0.78 & 0.86 & 0.63 & 0.68 & 0.70 & 0.75 \\
\hline$\check{R} g \check{g}$ & 0.89 & 0.30 & 0.89 & 0.93 & 0.79 & 0.82 & 0.84 & 0.87 \\
\hline$C^{2} I N T$ & 0.01 & 0.40 & 0.14 & 0.05 & 0.22 & 0.20 & 0.00 & 0.25 \\
\hline$\check{r} g_{l o c}$ & 0.98 & 0.09 & 0.76 & 0.91 & 0.57 & 0.62 & 0.98 & 0.66 \\
\hline$C V g_{(\%)}$ & 54.46 & 20.13 & 7.27 & 13.29 & 9.10 & 9.46 & 6.29 & 22.82 \\
\hline$C V e_{(\%)}$ & 77.14 & 77.63 & 7.04 & 12.66 & 11.68 & 11.16 & 11.45 & 17.45 \\
\hline Overall mean & 4.93 & 6.81 & 137.16 & 4.19 & 5.89 & 5.63 & 5.98 & 4.12 \\
\hline \multicolumn{9}{|c|}{ 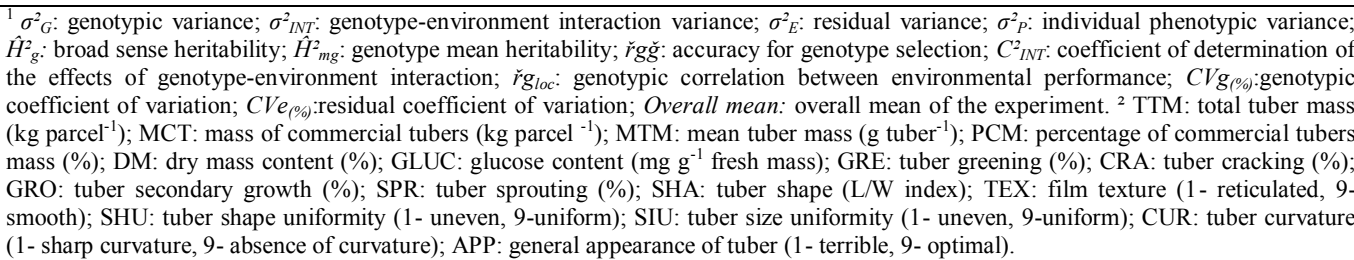 } \\
\hline
\end{tabular}


Regarding the variance components, phenotypic magnitude is related to environmental effects, genetic variation and interaction of genotypes with the environment, thus establishing a relationship between individual phenotypic variance $\left(\sigma^{2} \mathrm{~F}\right)$ and genotypic variance $\left(\sigma^{2} \mathrm{G}\right)$, it is possible to show that the evaluated characters were determined from $1.7 \%$ to $49.8 \%$ due to the genotypic effect. The highest genotypic influences were observed for TEX (49.8\%), APP (47.6\%), GLUC (47.2\%), SHA (44.4\%), DM (34.7\%), PCM (34.7\%), SIU (33.3\%), GRO (33.0\%), SHU (29.3\%), CUR (23.0\%), MTM (21.7\%). While the characters GRE, CRA, SPR, MCT and TTM presented larger environmental influences in their phenotypic proportions.

The largest relative contributions of genotypic variation $\left(\sigma^{2} \mathrm{G}\right)$ to genotype $\mathrm{x}$ environment interaction variance $\left(\sigma^{2} \mathrm{INT}\right)$ were verified for GRO $(98.0 \%)$, CUR $(97.9 \%)$, TEX (90.7\%), GLUC (88.5\%), DM (82.7\%), SHA (76.0\%), PCM (75.3\%), MTM (70.3\%), APP (65.9\%), SIU (61.9\%) and TSU (56.7\%), however, the individual phenotypic variance $\left(\sigma^{2} \mathrm{P}\right)$ contributed superiorly in the characters GRE (95.0\%), SPR (91.3\%), PCM (65.2\%), TTM $(57.5 \%)$ and CRA (52.5\%). Heritability expresses the fraction of the genetic variance in the phenotypic variance and may indicate reliability and experimental accuracy of the phenotypic value in predicting genetic value. In the case of potatoes (asexual reproduction), heritability in the broad sense is of great importance because it allows exploring additive, dominance and epistatic effects (Silva et al., 2018).

Broad sense genotype mean heritability $\left(\hat{\mathrm{H}}^{2}{ }_{\mathrm{mg}}\right)$ is an important parameter for predicting the success of breeding in family selection, as it is estimated using averages as the unit of evaluation / selection in order to reduce experimental errors from proportional increment of the number of repetitions, thus is the quotient of interest to predict the success of the breeding (Carvalho, et al. 2017). In this study $\hat{\mathrm{H}}^{2} \mathrm{mg}$ was considered high for TEX (0.86) and GLUC (0.84); moderate for GRO (0.79), SHA (0.78), DM (0.76), APP (0.75), PCM (0.74), CUR (0.70), SIU (0.68), SHU (0.63) and MTM (0.62); and low for TTM (0.46), CRA (0.43), MCT (0.37), GRE (0.06) and SPR (0.09).

When estimating broad sense heritability for the total genotypic effects without interference from the genotype-environment interaction $\left(\hat{\mathrm{H}}^{2} \mathrm{~g}\right)$, we take into account the total phenotypic dispersion, which assumes importance when exploring the total phenotypic variance. The $\hat{\mathrm{H}}^{2} \mathrm{~g}$ showed moderate magnitudes for TEX $(0.50)$ and low magnitudes for APP (0.48), GLUC (0.47), SHA (0.44), DM (0.35), PCM (0.35), GRO (0.33), SIU (0.33), SHU (0.29), CUR (0.23) and MTM (0.22). Higher accuracy evidences high efficacy in inferring genotypic values, selection strategies and genetic gains to characters, as well as indicating that the experimental conduction was adequate to characterize higher families.

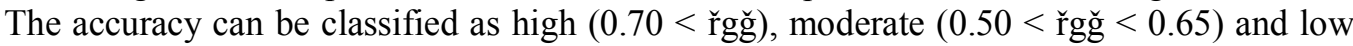
$(0.10<\check{\text { rggg }}<0.40)$. Given this, the high accuracy obtained for the characters PCM, MTM, GRO, GLUC, DM, SHA, TEX, SHU, SIU, CUR and APP, and moderate for MCT, TTM and CRA, show good experimental quality and therefore reliability in selecting superior genotypes for these characters. However, low accuracy was found for GRE and SPR, and their coefficients for determining the effects of genotype-environment interaction $\left(\mathrm{C}^{2}{ }_{\mathrm{INT}}\right)$, which allow quantifying how much of the total character variation is due to interaction effects showed that the meteorological particularities of the evaluated crops strongly influenced these traits, 0.40 and 0.32 , respectively.

The genotypic correlation between environmental performance $\left(\check{\mathrm{rg}}_{\mathrm{loc}}\right)$ reveals the nature of genotype-environment interaction, and indicates the reliability of family ordering 
in the tested environments. High $\breve{\mathrm{rg} g l o c}\left(\breve{\mathrm{rg}}_{\mathrm{loc}} \geq 0,50\right)$ was observed for the characters CUR (0.98), GRO (0.98), TEX (0.91), GLUC (0.88), DM (0.83), SHA (0.76), PCM (0.75), MTM (0.70), APP (0.66), SIU (0.62), SHU (0.57) which shows that the interaction is simple, that is, the classification of families has not substantially changed and selection can be made in one of these environments (Pupin et al., 2015). Low coefficients $\left(\breve{r}_{\text {loc }}<0.50\right)$ were observed for CRA (0.48), TTM (0.42), MCT (0.35), SPR (0.09) and GRE (0.05), in these cases, there is a greater effect of interaction with a complex nature, thus making it more difficult to select genotypes with phenotypic stability.

Regarding the coefficients of variation, GLUC, SHA, TEX and APP presented superiority of genotypic coefficient $(\mathrm{CVg})$ over residual $(\mathrm{CVe})$, reflecting a predominance of genetic effects and demonstrating a favorable situation for obtaining selection gains. Following these characters, the highest relations between $\mathrm{CVg}$ and $\mathrm{CVe}$ were obtained for SIU (0.84), PCM (0.80), SHU (0.78), DM (0.77) and GRO (0.71), and the lowest for MTM (0.56), CUR (0.55), TTM (0.50), CRA (0.42), MCT (0.41), SPR (0.26) and GRE (0.16).

The characters TTM, MCT, CRA, GRE and SPR are complex in nature, controlled by a large number of genes and thus subject to greater environmental influence (Nitithamyong et al., 1999; Slater et al., 2014), this was verified in the present study from the low estimated heritability, as well as due to the low genotypic correlation between the environmental performance. However, as regards the characters DM, GLUC, GRO, PCM, MTM and APP, which are also complex in nature (Slater et al., 2014), when evaluated in the present study, showed moderate and high heritability estimates, and were little influenced by the environment, given the greater contribution of genetic variance in the genotype-environment interaction.

Importantly, although high heritability has been obtained for GLUC, when tubers are subjected to storage at low temperatures, the accumulation of reducing sugars is subject to great environmental influence (Sun et al., 2018), and in these cases the estimated heritability has been of low magnitude (Salamoni et al., 2000). Therefore, low glucose levels at harvest will not necessarily guarantee success with selection for cold resistance during storage (Herman et al., 2016). Regarding SHA, TEX, CUR, SHU and SIU, the moderate estimated heritability and the high contribution of genetic variance in the interaction of genotype-growing environment, verified here, were predicted, because these traits are controlled by few genes, therefore, little influenced by the environment (Slater et al., 2014).

Knowledge of predicted genotypic values and gains from selecting a hybrid combination can be useful for predicting the outcome of the crossing. Selection gain should be evaluated using both the average of the crops as well as for each crop in order to ascertain whether greater genetic progress is achieved by selecting families for a specific environment (Simon et al., 2009). The genotype-environment interaction, which was significant for the evaluated characters, reinforces the importance of observing more stable families in the face of environmental variations, and more responsive to the improvement in environmental conditions. In this case, there is the possibility of estimating the genetic value $(\mathrm{g})$, predicted genotypic value $(\mathrm{u}+\mathrm{g})$, average predicted genotypic value $(\mathrm{u}+\mathrm{g}+$ gem), the gain with selection (Gain) and the new average with the selection (N Average) for both evaluated environments, as well as in each environment, through the use of BLUP.

In the verification of the total tuber mass character (Table 3), the families with the highest genetic values (g), which are free of interaction (Bastos et al., 2007), were 8 
(BRSIPR Bel x IAC-Ibituaçu) and 36 (BRSIPR Bel x Cupido), contributing respectively to the increase of 0.42 and $0.26 \mathrm{~kg}$ per share in the overall average. The predicted genotypic values $(\mathrm{u}+\mathrm{g})$, ie the overall average capitalized by the genetic values (Silva et al., 2018), would be 2.32 and $2.16 \mathrm{~kg}$ per plot, respectively. As family 8 was superior to the others, if this family is selected, it will contribute a gain in the same proportion of its genetic value, the equivalent of $0.42 \mathrm{~kg}$ per plot and the new general average would be kept at its predicted maximum $2.32 \mathrm{~kg}$ per plot. . If family 36 is included in the selection for this character, the gain will be $0.36 \mathrm{~kg}$ per plot and the new estimated average will be $2.27 \mathrm{~kg}$ per plot. Families 27 (F88-01-05 x Monalisa) and 35 (Caesar x C2514-05-06) had the worst performances for this character, presenting the lowest genetic values.

Table 3. Genetic values $(\mathrm{g})$, predicted genotypic values $(\mathrm{u}+\mathrm{g})$, average genotypic value $(\mathrm{u}+\mathrm{g}+\mathrm{gem})$, gains, new average with selection (N Average), evaluation of 20 potato families and 6 control cultivars, for the character total tuber mass, in the spring 2017 and summer 2017/2018 crops in Pelotas-RS. Embrapa, Pelotas, 2020. ${ }^{1}$ BRSIPR Bel; ${ }^{2}$ Epagri 361 -Catucha; ${ }^{3}$ BRS Eliza.

\begin{tabular}{|c|c|c|c|c|c|c|c|c|c|c|c|c|c|}
\hline \multirow{2}{*}{ Genotypes } & \multicolumn{5}{|c|}{ General } & \multicolumn{4}{|c|}{ Spring } & \multicolumn{4}{|c|}{ Summer } \\
\hline & g & $\mathbf{u}+\mathbf{g}$ & $\mathbf{u}+\mathrm{g}+\mathrm{gem}$ & Gain & N Average & G & $\mathbf{u}+\mathbf{g}$ & Gain & N Average & g & $\mathbf{u}+\mathbf{g}$ & Gain & N Average \\
\hline 8 & 0.42 & 2.32 & 2.61 & 0,42 & 2.32 & 0.93 & 3.75 & 0.93 & 3.75 & 0.47 & 1.46 & 0.65 & 1.64 \\
\hline 36 & 0.26 & 2.16 & 2.34 & 0.36 & 2.27 & 0.70 & 3.53 & 0.81 & 3.64 & 0.16 & 1.15 & 0.47 & 1.46 \\
\hline 34 & 0.22 & 2.12 & 2.27 & 0.32 & 2.23 & 0.15 & 2.97 & 0.39 & 3.22 & 0.58 & 1.56 & 0.74 & 1.73 \\
\hline 12 & 0.14 & 2.05 & 2.14 & 0.29 & 2.19 & 0.16 & 2.99 & 0.47 & 3.30 & 0.31 & 1.30 & 0.53 & 1.52 \\
\hline 26 & 0.05 & 1.96 & 1.99 & 0.23 & 2.14 & 0.15 & 2.98 & 0.43 & 3.25 & 0.01 & 1.00 & 0.31 & 1.30 \\
\hline 7 & 0.05 & 1.96 & 1.99 & 0.21 & 2.11 & 0.32 & 3.15 & 0.59 & 3.42 & -0.16 & 0.83 & 0.15 & 1.14 \\
\hline 37 & 0.03 & 1.94 & 1.96 & 0.19 & 2.09 & 0.14 & 2.97 & 0.36 & 3.19 & -0.04 & 0.95 & 0.26 & 1.25 \\
\hline 11 & 0.01 & 1.92 & 1.93 & 0.17 & 2.08 & -0.10 & 2.73 & 0.25 & 3.08 & 0.14 & 1.13 & 0.42 & 1.41 \\
\hline 21 & -0.03 & 1.88 & 1.86 & 0.14 & 2.05 & -0.10 & 2.73 & 0.23 & 3.05 & 0.01 & 1.00 & 0.29 & 1.27 \\
\hline 20 & -0.07 & 1.84 & 1.80 & 0.10 & 2.01 & -0.17 & 2.65 & 0.13 & 2.95 & -0.05 & 0.94 & 0.24 & 1.22 \\
\hline 19 & -0.08 & 1.83 & 1.78 & 0.08 & 1.99 & -0.18 & 2.65 & 0.11 & 2.94 & -0.08 & 0.90 & 0.21 & 1.20 \\
\hline 13 & -0.08 & 1.82 & 1.77 & 0.07 & 1.98 & -0.11 & 2.72 & 0.20 & 3.03 & -0.17 & 0.81 & 0.13 & 1.12 \\
\hline 2 & -0.10 & 1.81 & 1.74 & 0.06 & 1.97 & -0.20 & 2.62 & 0.10 & 2.92 & -0.14 & 0.85 & 0.17 & 1.16 \\
\hline 18 & -0.12 & 1.79 & 1.71 & 0.05 & 1.96 & -0.30 & 2.53 & 0.08 & 2.90 & -0.10 & 0.89 & 0.19 & 1.18 \\
\hline 25 & -0.12 & 1.78 & 1.70 & 0.05 & 1.95 & -0.17 & 2.66 & 0.16 & 2.99 & -0.25 & 0.74 & 0.08 & 1.07 \\
\hline 5 & -0.15 & 1.75 & 1.65 & 0.04 & 1.94 & -0.17 & 2.66 & 0.18 & 3.01 & -0.35 & 0.64 & 0.03 & 1.02 \\
\hline 16 & -0.16 & 1.75 & 1.64 & 0.03 & 1.94 & -0.17 & 2.66 & 0.14 & 2.97 & -0.36 & 0.62 & 0.02 & 1.01 \\
\hline 17 & -0.20 & 1.71 & 1.57 & 0.02 & 1.93 & -0.39 & 2.44 & 0.04 & 2.87 & -0.28 & 0.71 & 0.07 & 1.05 \\
\hline 35 & -0.22 & 1.69 & 1.54 & 0.01 & 1.92 & -0.43 & 2.40 & 0.02 & 2.85 & -0.31 & 0.68 & 0.05 & 1.04 \\
\hline 27 & -0.22 & 1.69 & 1.53 & 0.00 & 1.91 & -0.51 & 2.31 & 0.00 & 2.83 & -0.23 & 0.76 & 0.10 & 1.09 \\
\hline $\mathrm{Bel}^{1}$ & 0.40 & 2.31 & 2.58 & 0.41 & 2.32 & 0.43 & 3.25 & 0.69 & 3.51 & 0.91 & 1.90 & 0.91 & 1.90 \\
\hline Catucha ${ }^{2}$ & 0.13 & 2.04 & 2.12 & 0.26 & 2.17 & 0.05 & 2.88 & 0.31 & 3.14 & 0.38 & 1.37 & 0.59 & 1.57 \\
\hline Asterix & 0.01 & 1.92 & 1.92 & 0.16 & 2.06 & -0.04 & 2.79 & 0.28 & 3.11 & 0.07 & 1.06 & 0.35 & 1.34 \\
\hline Eliza $^{3}$ & -0.03 & 1.88 & 1.85 & 0.13 & 2.03 & 0.07 & 2.90 & 0.34 & 3.16 & -0.18 & 0.81 & 0.12 & 1.11 \\
\hline Baronesa & -0.04 & 1.86 & 1.83 & 0.11 & 2.02 & 0.30 & 3.13 & 0.54 & 3.36 & -0.45 & 0.54 & 0.00 & 0.99 \\
\hline Atlantic & -0.08 & 1.83 & 1.78 & 0.09 & 2.00 & -0.37 & 2.46 & 0.06 & 2.88 & 0.11 & 1.10 & 0.38 & 1.37 \\
\hline
\end{tabular}

Considering the average interaction of the environments $(\mathrm{u}+\mathrm{g}+\mathrm{gem})$, which is equivalent to the average genotypic value of the two crops, it can be verified that the families 8 and 36 had the highest values: 2.61 and $2.34 \mathrm{~kg}$ per plot, respectively, presenting in addition to high genetic value, good performance against the environmental conditions considered in the interaction calculation.

When selecting more responsive families to spring growing conditions, families 8 and 36 remain with the highest genetic values $(\mathrm{g})$. However, in summer growing conditions, family 8 descends in the rank, and family 34 (BRSIPR Bel x Voyager) has the highest genetic value, and this lower reliability in the ordering of the tested families was already expected for the total tuber mass character, given the low genotypic correlation between environmental performance (0.42) (Table 2). It is noteworthy that cultivar BRSIPR Bel had 
the highest genetic value in summer growing, as well as the third largest genetic value in spring growing, and second highest value in the average interaction of environments.

Therefore, for the total tuber mass character (Table 4), it can be seen that family 8 stood out in relation to the others, as it had good performance in both spring and summer growing.

Table 4. Genetic values $(\mathrm{g})$, predicted genotypic values $(\mathrm{u}+\mathrm{g})$, average genotypic value $(\mathrm{u}+\mathrm{g}+\mathrm{gem})$, gains, new average with selection (N Average), evaluation of 20 potato families and 6 control cultivars, for the character mass of commercial tubers, in the spring 2017 and summer 2017/2018 crops in Pelotas-RS. Embrapa, Pelotas, 2020. ${ }^{1}$ BRSIPR Bel; ${ }^{2}$ Epagri 361-Catucha; ${ }^{3}$ BRS Eliza.

\begin{tabular}{|c|c|c|c|c|c|c|c|c|c|c|c|c|c|}
\hline \multirow{2}{*}{ Genotypes } & \multicolumn{5}{|c|}{ General } & \multicolumn{4}{|c|}{ Spring } & \multicolumn{4}{|c|}{ Summer } \\
\hline & g & $\mathbf{u}+\mathrm{g}$ & u+g+gem & Gain & N Average & G & $\mathbf{u}+\mathbf{g}$ & Gain & N Average & $\mathrm{g}$ & $\mathbf{u}+\mathbf{g}$ & Gain & N Average \\
\hline 36 & 0.14 & 0.99 & 1.12 & 0.17 & 1.03 & 0.49 & 1.81 & 0.49 & 1.81 & 0.04 & 0.43 & 0.22 & 0.61 \\
\hline 8 & 0.09 & 0.95 & 1.04 & 0.15 & 1.01 & 0.33 & 1.65 & 0.40 & 1.72 & 0.03 & 0.43 & 0.19 & 0.59 \\
\hline 7 & 0.08 & 0.94 & 1.02 & 0.14 & 1.00 & 0.36 & 1.68 & 0.42 & 1.74 & -0.03 & 0.36 & 0.12 & 0.52 \\
\hline 34 & 0.07 & 0.92 & 0.99 & 0.12 & 0.98 & 0.20 & 1.52 & 0.33 & 1.65 & 0.06 & 0.46 & 0.29 & 0.68 \\
\hline 12 & 0.05 & 0.91 & 0.95 & 0.10 & 0.96 & 0.05 & 1.37 & 0.23 & 1.55 & 0.13 & 0.53 & 0.34 & 0.74 \\
\hline 20 & 0.03 & 0.88 & 0.91 & 0.10 & 0.95 & 0.07 & 1.39 & 0.30 & 1.62 & 0.03 & 0.42 & 0.18 & 0.57 \\
\hline 21 & 0.02 & 0.88 & 0.90 & 0.09 & 0.95 & 0.07 & 1.39 & 0.27 & 1.59 & 0.01 & 0.41 & 0.15 & 0.54 \\
\hline 13 & 0.00 & 0.85 & 0.85 & 0.08 & 0.93 & 0.06 & 1.38 & 0.25 & 1.57 & -0.07 & 0.33 & 0.10 & 0.49 \\
\hline 37 & -0.03 & 0.83 & 0.81 & 0.07 & 0.93 & -0.01 & 1.31 & 0.20 & 1.52 & -0.09 & 0.30 & 0.09 & 0.48 \\
\hline 26 & -0.03 & 0.83 & 0.81 & 0.06 & 0.92 & -0.01 & 1.31 & 0.18 & 1.50 & -0.09 & 0.30 & 0.08 & 0.47 \\
\hline 11 & -0.03 & 0.83 & 0.80 & 0.06 & 0.92 & -0.18 & 1.14 & 0.07 & 1.39 & 0.06 & 0.45 & 0.25 & 0.64 \\
\hline 2 & -0.06 & 0.79 & 0.74 & 0.05 & 0.90 & -0.14 & 1.18 & 0.15 & 1.47 & -0.11 & 0.29 & 0.05 & 0.44 \\
\hline 16 & -0.08 & 0.78 & 0.71 & 0.04 & 0.90 & -0.17 & 1.15 & 0.08 & 1.40 & -0.13 & 0.27 & 0.04 & 0.44 \\
\hline 5 & -0.08 & 0.78 & 0.71 & 0.03 & 0.89 & -0.14 & 1.18 & 0.13 & 1.45 & -0.16 & 0.24 & 0.03 & 0.43 \\
\hline 35 & -0.08 & 0.78 & 0.70 & 0.03 & 0.89 & -0.21 & 1.11 & 0.06 & 1.38 & -0.09 & 0.30 & 0.07 & 0.46 \\
\hline 25 & -0.08 & 0.78 & 0.70 & 0.02 & 0.88 & -0.16 & 1.16 & 0.11 & 1.43 & -0.16 & 0.24 & 0.02 & 0.42 \\
\hline 17 & -0.10 & 0.76 & 0.67 & 0.02 & 0.88 & -0.27 & 1.04 & 0.04 & 1.36 & -0.10 & 0.30 & 0.06 & 0.45 \\
\hline 19 & -0.12 & 0.74 & 0.63 & 0.01 & 0.87 & -0.30 & 1.02 & 0.03 & 1.35 & -0.16 & 0.23 & 0.02 & 0.41 \\
\hline 18 & -0.13 & 0.72 & 0.60 & 0.01 & 0.86 & -0.35 & 0.97 & 0.02 & 1.33 & -0.17 & 0.23 & 0.01 & 0.40 \\
\hline 27 & -0.16 & 0.70 & 0.56 & 0.00 & 0.86 & -0.38 & 0.93 & 0.00 & 1.32 & -0.22 & 0.18 & 0.00 & 0.40 \\
\hline $\mathrm{Bel}^{1}$ & 0.24 & 1.10 & 1.33 & 0.24 & 1.10 & 0.42 & 1.74 & 0.45 & 1.77 & 0.53 & 0.92 & 0.53 & 0.92 \\
\hline Atlantic & 0.14 & 1.00 & 1.13 & 0.19 & 1.05 & 0.01 & 1.33 & 0.22 & 1.54 & 0.52 & 0.92 & 0.52 & 0.92 \\
\hline Baronesa & 0.08 & 0.93 & 1.00 & 0.13 & 0.99 & 0.27 & 1.59 & 0.37 & 1.69 & 0.02 & 0.41 & 0.16 & 0.56 \\
\hline Eliza $^{3}$ & 0.06 & 0.92 & 0.97 & 0.11 & 0.97 & 0.26 & 1.58 & 0.36 & 1.68 & -0.04 & 0.36 & 0.11 & 0.51 \\
\hline Catucha $^{2}$ & 0.02 & 0.88 & 0.90 & 0.08 & 0.94 & -0.11 & 1.21 & 0.16 & 1.48 & 0.19 & 0.59 & 0.41 & 0.81 \\
\hline Asterix & -0.04 & 0.81 & 0.77 & 0.05 & 0.91 & -0.17 & 1.15 & 0.10 & 1.42 & 0.00 & 0.39 & 0.13 & 0.53 \\
\hline
\end{tabular}

For the mass of commercial tubers character, considering the average interaction of the environments $(u+g+$ gem), it was verified that the families 36 and 8 had the highest values: 1.12 and $1.04 \mathrm{~kg}$ of commercial tubers per plot. However, the ordering of the upper families was different in each growing period, which is in accordance with the low genotypic correlation between environmental performance (0.35) (Table 2). In spring growing conditions, family 36 was superior, and if selected, the gain and the new general average will be 0.49 and $1.81 \mathrm{~kg}$ of commercial tubers per plot, respectively. However, if one is looking for a family that is more responsive to the typical conditions of summer growing, family 12 (BRSIPR Bel x C1883-22-97) obtained a higher genetic value, contributing to a $0.13 \mathrm{~kg}$ increase in commercial tubers per plot in the general average, with a predicted genotypic value of $0.53 \mathrm{~kg}$ of commercial tubers per plot, and if selected, the gain and new overall average will be 0.34 and $0.74 \mathrm{~kg}$ of commercial tubers per plot. The cultivar BRSIPR Bel presented higher value in the medium interaction of environments, as well as higher genetic value in summer growing, and second highest genetic value in spring growing. 
Thus, for the mass of commercial tubers character, although families 36 and 8 had the highest average genotypic value, it appears that family 36 was more responsive to spring growing conditions, and family 12 to summer. The cultivar BRSIPR Bel stood out because it had good performance in both crops.

Regarding the mean tuber mass (Table 5), the two families with the highest average genotypic value of the two crops $(\mathrm{u}+\mathrm{g}+\mathrm{gem})$ were 12 and 36, with values of 48.52 and $48.43 \mathrm{~g}$ per tuber, respectively. In the spring and summer crops, family 36 was between the two families with the highest genetic values (g), as well as the Atlantic and BRSIPR Bel cultivars.

Table 5. Genetic values $(\mathrm{g})$, predicted genotypic values $(\mathrm{u}+\mathrm{g})$, average genotypic value $(\mathrm{u}+\mathrm{g}+\mathrm{gem})$, gains, new average with selection (N Average), evaluation of 20 potato families and 6 control cultivars, for the character mean tuber mass, in the spring 2017 and summer 2017/2018 crops in Pelotas-RS. Embrapa,

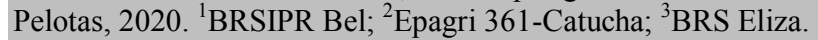

\begin{tabular}{|c|c|c|c|c|c|c|c|c|c|c|c|c|c|}
\hline \multirow{2}{*}{ Genotypes } & \multicolumn{5}{|c|}{ General } & \multicolumn{4}{|l|}{ Spring } & \multicolumn{4}{|c|}{ Summer } \\
\hline & g & $\mathbf{u + g}$ & $\mathbf{u}+\mathrm{g}+\mathrm{gem}$ & Gain & N Average & G & $u+g$ & Gain & N Average & g & $u+g$ & Gain & N Average \\
\hline 12 & 3.66 & 47.75 & 48.52 & 6.56 & 50.65 & 3.14 & 61.00 & 5.83 & 63.69 & 5.72 & 36.04 & 9.67 & 39.99 \\
\hline 36 & 3.58 & 47.67 & 48.43 & 5.96 & 50.05 & 3.45 & 61.32 & 6.37 & 64.23 & 5.22 & 35.54 & 8.78 & 39.10 \\
\hline 13 & 2.55 & 46.64 & 47.17 & 5.40 & 49.48 & 3.77 & 61.63 & 7.10 & 64.96 & 2.41 & 32.72 & 6.77 & 37.08 \\
\hline 11 & 2.17 & 46.26 & 46.71 & 4.93 & 49.02 & 0.95 & 58.81 & 4.16 & 62.02 & 4.30 & 34.61 & 8.04 & 38.35 \\
\hline 20 & 1.74 & 45.83 & 46.20 & 4.53 & 48.62 & 0.71 & 58.57 & 3.60 & 61.46 & 3.51 & 33.82 & 7.39 & 37.70 \\
\hline 21 & 1.55 & 45.64 & 45.97 & 4.20 & 48.29 & 2.10 & 59.96 & 4.94 & 62.80 & 1.66 & 31.97 & 6.20 & 36.51 \\
\hline 8 & 0.41 & 44.50 & 44.59 & 3.61 & 47.70 & 1.16 & 59.02 & 4.52 & 62.38 & -0.16 & 30.15 & 5.15 & 35.47 \\
\hline 26 & 0.12 & 44.21 & 44.24 & 3.08 & 47.17 & 0.92 & 58.78 & 3.86 & 61.73 & -0.62 & 29.70 & 4.67 & 34.99 \\
\hline 2 & -0.43 & 43.66 & 43.57 & 2.83 & 46.92 & 0.14 & 58.00 & 3.14 & 61.00 & -1.18 & 29.14 & 4.22 & 34.54 \\
\hline 35 & -0.70 & 43.39 & 43.24 & 2.59 & 46.68 & -0.15 & 57.71 & 2.92 & 60.78 & -1.55 & 28.77 & 3.47 & 33.78 \\
\hline 34 & -1.39 & 42.70 & 42.40 & 2.35 & 46.43 & 0.54 & 58.40 & 3.37 & 61.23 & -3.91 & 26.41 & 1.91 & 32.22 \\
\hline 25 & -1.63 & 42.46 & 42.11 & 2.11 & 46.20 & -2.62 & 55.24 & 1.99 & 59.85 & -1.33 & 28.98 & 3.83 & 34.14 \\
\hline 17 & -1.90 & 42.18 & 41.78 & 1.89 & 45.98 & -2.22 & 55.64 & 2.25 & 60.11 & -2.39 & 27.92 & 2.82 & 33.13 \\
\hline 7 & -2.10 & 41.99 & 41.55 & 1.68 & 45.77 & -0.47 & 57.39 & 2.70 & 60.57 & -4.61 & 25.70 & 1.34 & 31.65 \\
\hline 37 & -2.64 & 41.45 & 40.89 & 1.46 & 45.55 & -3.87 & 53.99 & 1.70 & 59.56 & -2.53 & 27.79 & 2.52 & 32.83 \\
\hline 27 & -3.36 & 40.72 & 40.01 & 1.23 & 45.32 & -4.87 & 52.99 & 1.12 & 58.98 & -3.28 & 27.04 & 2.21 & 32.53 \\
\hline 18 & -3.61 & 40.47 & 39.71 & 1.01 & 45.10 & -4.56 & 53.30 & 1.40 & 59.26 & -4.20 & 26.12 & 1.62 & 31.93 \\
\hline 19 & -4.91 & 39.18 & 38.14 & 0.75 & 44.84 & -5.75 & 52.11 & 0.55 & 58.41 & -6.14 & 24.17 & 1.01 & 31.32 \\
\hline 5 & -5.19 & 38.90 & 37.80 & 0.51 & 44.59 & -5.59 & 52.27 & 0.83 & 58.69 & -6.99 & 23.33 & 0.68 & 30.99 \\
\hline 16 & -6.14 & 37.95 & 36.65 & 0.00 & 44.09 & -6.01 & 51.85 & 0.29 & 58.15 & -8.86 & 21.45 & 0.00 & 30.31 \\
\hline Atlantic & 10.27 & 54.35 & 56.52 & 10.27 & 54.35 & 11.08 & 68.94 & 11.08 & 68.94 & 13.79 & 44.10 & 13.79 & 44.10 \\
\hline $\mathrm{Bel}^{1}$ & 8.24 & 52.33 & 54.07 & 9.25 & 53.34 & 8.24 & 66.10 & 9.66 & 67.52 & 11.73 & 42.04 & 12.76 & 43.07 \\
\hline Catucha $^{2}$ & 4.07 & 48.16 & 49.02 & 7.53 & 51.61 & 2.40 & 60.26 & 5.34 & 63.20 & 7.46 & 37.77 & 10.99 & 41.31 \\
\hline Baronesa & 1.47 & 45.56 & 45.87 & 3.93 & 48.02 & 5.29 & 63.15 & 8.20 & 66.06 & -1.72 & 28.59 & 3.14 & 33.46 \\
\hline Eliza $^{3}$ & 0.20 & 44.29 & 44.33 & 3.33 & 47.41 & -0.56 & 57.30 & 2.51 & 60.37 & 1.05 & 31.36 & 5.68 & 36.00 \\
\hline Asterix & -6.03 & 38.06 & 36.78 & 0.25 & 44.33 & -7.23 & 50.63 & 0.00 & 57.86 & -7.38 & 22.94 & 0.35 & 30.67 \\
\hline
\end{tabular}

Regarding the percentage of commercial tuber mass (Table 6), when considering the average genotypic value of the two crops $(u+g+$ gem), it appears that family 20 (Markies x C1883-22-97) had the highest value, of 45.40\%. In spring and summer growing, it was also found higher genetic value for family 20 , of 7.02 and $12.76 \%$, respectively. The cultivars Atlantic and BRSIPR Bel had the highest average genotypic values of both crops, as well as the highest genetic values in spring and summer.

The authors Pinto et al. (2010) and Silva et al. (2016), when verifying the productive potential of cultivar Asterix in six and two environments, respectively, observed its inferior performance in relation to several clones tested, such results corroborate with those obtained in this study according to Silva et al. (2014), this is probably due to the problems of adaptation of foreign cultivars to the edaphoclimatic conditions of Brazil. Similarly Souza et al. (2007) found 
large differences in the performance of genotypes evaluated in different environments, thus demonstrating that genotype-environment interaction is important in potato crop.

Table 6. Genetic values $(\mathrm{g})$, predicted genotypic values $(\mathrm{u}+\mathrm{g})$, average genotypic value $(\mathrm{u}+\mathrm{g}+\mathrm{gem})$, gains, new average with selection (N Average), evaluation of 20 potato families and 6 control cultivars, for the character percentage of commercial tuber mass in the spring 2017 and summer 2017/2018 crops in

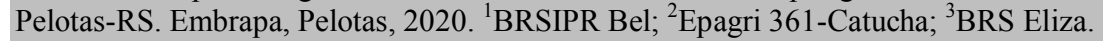

\begin{tabular}{|c|c|c|c|c|c|c|c|c|c|c|c|c|c|}
\hline \multirow{2}{*}{ Genotypes } & \multicolumn{5}{|l|}{ General } & \multicolumn{4}{|l|}{ Spring } & \multicolumn{4}{|l|}{ Summer } \\
\hline & g & $\mathbf{u}+\mathbf{g}$ & $\mathbf{u}+\mathbf{g}+\mathbf{g e m}$ & Gain & N Average & G & $\mathbf{u}+\mathbf{g}$ & Gain & N Average & $\mathrm{g}$ & $\mathbf{u}+\mathbf{g}$ & Gain & N Average \\
\hline 20 & 8.50 & 44.01 & 45.40 & 16.12 & 51.63 & 7.02 & 50.90 & 13.88 & 57.77 & 12.76 & 39.90 & 22.12 & 49.26 \\
\hline 12 & 4.68 & 40.19 & 40.96 & 10.57 & 46.09 & 3.71 & 47.59 & 9.24 & 53.12 & 7.17 & 34.32 & 16.92 & 44.06 \\
\hline 36 & 4.09 & 39.60 & 40.27 & 9.65 & 45.16 & 5.94 & 49.83 & 12.30 & 56.18 & 3.57 & 30.71 & 11.94 & 39.08 \\
\hline 21 & 2.08 & 37.59 & 37.93 & 8.70 & 44.21 & 3.85 & 47.73 & 10.03 & 53.91 & 0.99 & 28.14 & 10.72 & 37.87 \\
\hline 34 & 1.42 & 36.94 & 37.17 & 7.89 & 43.40 & 3.20 & 47.09 & 8.57 & 52.45 & 0.10 & 27.25 & 9.66 & 36.81 \\
\hline 13 & 0.95 & 36.46 & 36.62 & 7.20 & 42.71 & 2.31 & 46.19 & 7.05 & 50.93 & -0.10 & 27.04 & 8.78 & 35.92 \\
\hline 11 & 0.08 & 35.60 & 35.61 & 6.01 & 41.53 & -3.45 & 40.43 & 4.93 & 48.81 & 3.64 & 30.78 & 13.14 & 40.28 \\
\hline 8 & -0.46 & 35.05 & 34.98 & 5.52 & 41.03 & 2.46 & 46.34 & 7.48 & 51.36 & -3.53 & 23.61 & 5.74 & 32.89 \\
\hline 7 & -0.75 & 34.77 & 34.64 & 5.07 & 40.58 & 4.86 & 48.74 & 11.06 & 54.94 & -6.59 & 20.55 & 3.90 & 31.04 \\
\hline 37 & -1.31 & 34.21 & 33.99 & 4.64 & 40.16 & -1.21 & 42.68 & 5.49 & 49.37 & -1.84 & 25.30 & 7.89 & 35.03 \\
\hline 2 & -2.03 & 33.49 & 33.16 & 4.23 & 39.74 & -1.13 & 42.76 & 5.97 & 49.85 & -3.59 & 23.55 & 5.16 & 32.30 \\
\hline 26 & -4.87 & 30.64 & 29.84 & 3.30 & 38.81 & -4.16 & 39.73 & 4.39 & 48.28 & -7.18 & 19.96 & 2.82 & 29.96 \\
\hline 35 & -5.49 & 30.03 & 29.13 & 2.83 & 38.35 & -6.17 & 37.71 & 3.32 & 47.21 & -6.60 & 20.54 & 3.34 & 30.49 \\
\hline 17 & -5.58 & 29.93 & 29.02 & 2.41 & 37.93 & -7.15 & 36.73 & 2.80 & 46.68 & -5.84 & 21.30 & 4.51 & 31.66 \\
\hline 25 & -6.52 & 28.99 & 27.93 & 1.99 & 37.50 & -7.17 & 36.72 & 2.32 & 46.21 & -8.01 & 19.14 & 2.30 & 29.45 \\
\hline 5 & -6.98 & 28.53 & 27.39 & 1.58 & 37.09 & -7.41 & 36.48 & 1.88 & 45.77 & -8.84 & 18.30 & 0.94 & 28.08 \\
\hline 27 & -7.87 & 27.64 & 26.35 & 1.17 & 36.68 & -9.64 & 34.24 & 0.97 & 44.86 & -8.68 & 18.46 & 1.37 & 28.51 \\
\hline 18 & -8.25 & 27.26 & 25.91 & 0.78 & 36.29 & -10.92 & 32.96 & 0.50 & 44.38 & -8.28 & 18.86 & 1.82 & 28.96 \\
\hline 16 & -8.37 & 27.14 & 25.77 & 0.41 & 35.92 & -8.40 & 35.49 & 1.44 & 45.32 & -11.08 & 16.06 & 0.46 & 27.60 \\
\hline 19 & -10.28 & 25.24 & 23.55 & 0.00 & 35.51 & -12.44 & 31.44 & 0.00 & 43.88 & -11.47 & 15.67 & 0.00 & 27.14 \\
\hline Atlantic & 28.18 & 63.70 & 68.31 & 28.18 & 63.70 & 27.74 & 71.62 & 27.74 & 71.62 & 37.85 & 65.00 & 37.85 & 65.00 \\
\hline $\mathrm{Bel}^{1}$ & 11.67 & 47.19 & 49.10 & 19.93 & 55.44 & 11.43 & 55.31 & 19.58 & 63.47 & 15.74 & 42.88 & 26.80 & 53.94 \\
\hline Eliza $^{3}$ & 5.62 & 41.14 & 42.06 & 13.49 & 49.01 & 9.35 & 53.24 & 16.17 & 60.06 & 3.74 & 30.88 & 14.72 & 41.86 \\
\hline Catucha $^{2}$ & 4.78 & 40.29 & 41.07 & 11.75 & 47.26 & 0.07 & 43.95 & 6.51 & 50.40 & 11.05 & 38.20 & 19.35 & 46.49 \\
\hline Baronesa & 0.11 & 35.62 & 35.64 & 6.55 & 42.07 & 2.71 & 46.59 & 7.98 & 51.87 & -2.45 & 24.69 & 7.10 & 34.24 \\
\hline Asterix & -3.41 & 32.11 & 31.55 & 3.78 & 39.29 & -5.40 & 38.48 & 3.85 & 47.73 & -2.53 & 24.61 & 6.41 & 33.55 \\
\hline
\end{tabular}

Regarding the dry mass content (Table 7) for the processed product to have good texture, crispness and high industrial yield, the content of this character must be between 20 and 24\%. Thus, the families 8 (BRSIPR Bel x IAC-Ibituaçu), 5 (C2519-12-06 x 118-1) and 12 (BRSIPR Bel x C1883-22-97) presented the highest genetic values (g), contributing respectively to the increase of $2.11,1.02$ and $0.97 \%$ in the overall average. If family 8 is selected, it will contribute a gain of $2.11 \%$, and the new overall average will be $22.34 \%$, while family 5 will contribute a gain of $1.53 \%$, with a new average of $21,76 \%$, while if family 12 is selected, the gain will be $1.39 \%$ and the new average $21.62 \%$.

In addition to the high genotypic value, families 8,5 and 12 presented a good performance in relation to the environmental conditions considered in the interaction calculation, since they presented the highest values of the average environment interaction $(u+g+$ gem) of $22.56,21.36$ and $21.31 \%$, respectively.

In spring growing conditions, families 8,5 and 12 remained with the highest genetic values: $2.60,1.26$ and $0.92 \%$, respectively. However, under summer growing conditions, family 5 decreased by $0.99 \%$, while families 8 and 12 continued with the highest genetic values: $2.06 \%$ and $1.23 \%$, respectively. It is noteworthy that the cultivar Epagri 361-Catucha presented the second highest genetic value in spring and summer growing, as well as the second highest value in the average interaction of environments. 
Therefore, for the dry mass content character, it is verified that the families 8 and 12 stood out in relation to the others, as they had good performance in both spring and summer growing.

Table 7. Genetic values $(\mathrm{g})$, predicted genotypic values $(\mathrm{u}+\mathrm{g})$, average genotypic value $(\mathrm{u}+\mathrm{g}+\mathrm{gem})$, gains, new average with selection (N Average), evaluation of 20 potato families and 6 control cultivars, for the character dry mass content, in the spring 2017 and summer 2017/2018 crops in Pelotas-RS. Embrapa,

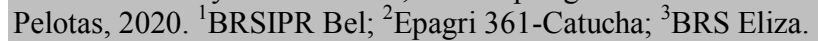

\begin{tabular}{|c|c|c|c|c|c|c|c|c|c|c|c|c|c|}
\hline \multirow{2}{*}{ Genotypes } & \multicolumn{5}{|c|}{ General } & \multicolumn{4}{|c|}{ Spring } & \multicolumn{4}{|c|}{ Summer } \\
\hline & g & $u+g$ & u+g+gem & Gain & N Average & $\mathrm{g}$ & $\mathbf{u}+\mathbf{g}$ & Gain & N Average & $\mathrm{g}$ & $\mathbf{u}+\mathrm{g}$ & Gain & N Average \\
\hline 8 & 2.11 & 22.34 & 22.56 & 2.11 & 22.34 & 2.60 & 23.93 & 2.60 & 23.93 & 2.06 & 21.19 & 2.06 & 21.19 \\
\hline 5 & 1.02 & 21.25 & 21.36 & 1.53 & 21.76 & 1.26 & 22.59 & 1.86 & 23.19 & 0.99 & 20.13 & 1.38 & 20.52 \\
\hline 12 & 0.97 & 21.21 & 21.31 & 1.39 & 21.62 & 0.92 & 22.25 & 1.62 & 22.95 & 1.23 & 20.37 & 1.60 & 20.74 \\
\hline 11 & 0.73 & 20.97 & 21.04 & 1.20 & 21.43 & 0.70 & 22.03 & 1.28 & 22.61 & 0.92 & 20.05 & 1.31 & 20.44 \\
\hline 36 & 0.69 & 20.92 & 20.99 & 1.13 & 21.36 & 0.91 & 22.24 & 1.48 & 22.81 & 0.61 & 19.75 & 1.05 & 20.19 \\
\hline 35 & 0.56 & 20.79 & 20.85 & 1.01 & 21.24 & 0.54 & 21.87 & 1.08 & 22.41 & 0.68 & 19.82 & 1.16 & 20.30 \\
\hline 19 & 0.55 & 20.78 & 20.84 & 0.96 & 21.19 & 0.44 & 21.77 & 1.02 & 22.35 & 0.77 & 19.90 & 1.23 & 20.37 \\
\hline 26 & 0.28 & 20.51 & 20.54 & 0.90 & 21.13 & 0.23 & 21.56 & 0.91 & 22.24 & 0.39 & 19.53 & 0.99 & 20.13 \\
\hline 37 & 0.23 & 20.46 & 20.49 & 0.84 & 21.08 & 0.20 & 21.53 & 0.86 & 22.19 & 0.31 & 19.45 & 0.94 & 20.07 \\
\hline 20 & 0.21 & 20.45 & 20.47 & 0.79 & 21.03 & 0.55 & 21.88 & 1.14 & 22.47 & -0.08 & 19.06 & 0.77 & 19.90 \\
\hline 7 & 0.08 & 20.31 & 20.32 & 0.74 & 20.98 & 0.39 & 21.72 & 0.97 & 22.30 & -0.21 & 18.93 & 0.71 & 19.84 \\
\hline 2 & 0.01 & 20.24 & 20.25 & 0.69 & 20.93 & -0.07 & 21.26 & 0.72 & 22.05 & 0.09 & 19.23 & 0.83 & 19.96 \\
\hline 25 & 0.00 & 20.24 & 20.24 & 0.65 & 20.88 & -0.22 & 21.11 & 0.66 & 21.99 & 0.23 & 19.36 & 0.88 & 20.02 \\
\hline 18 & -0.07 & 20.16 & 20.15 & 0.61 & 20.84 & 0.14 & 21.47 & 0.81 & 22.14 & -0.30 & 18.83 & 0.65 & 19.78 \\
\hline 21 & -0.44 & 19.79 & 19.74 & 0.50 & 20.73 & -0.60 & 20.73 & 0.60 & 21.93 & -0.38 & 18.75 & 0.59 & 19.72 \\
\hline 17 & -0.80 & 19.44 & 19.35 & 0.44 & 20.67 & -0.99 & 20.34 & 0.46 & 21.79 & -0.77 & 18.37 & 0.52 & 19.65 \\
\hline 27 & -1.23 & 19.00 & 18.87 & 0.23 & 20.47 & -1.69 & 19.64 & 0.27 & 21.60 & -1.03 & 18.10 & 0.31 & 19.45 \\
\hline 16 & -1.45 & 18.78 & 18.63 & 0.16 & 20.40 & -1.94 & 19.39 & 0.10 & 21.43 & -1.27 & 17.86 & 0.24 & 19.38 \\
\hline 13 & -1.55 & 18.69 & 18.52 & 0.09 & 20.33 & -1.82 & 19.51 & 0.19 & 21.52 & -1.60 & 17.53 & 0.11 & 19.24 \\
\hline 34 & -2.37 & 17.87 & 17.62 & 0.00 & 20.23 & -2.55 & 18.78 & 0.00 & 21.33 & -2.67 & 16.46 & 0.00 & 19.14 \\
\hline Catucha $^{2}$ & 1.46 & 21.69 & 21.85 & 1.78 & 22.02 & 1.71 & 23.04 & 2.15 & 23.48 & 1.52 & 20.66 & 1.79 & 20.93 \\
\hline Atlantic & 0.91 & 21.14 & 21.24 & 1.29 & 21.53 & 0.89 & 22.22 & 1.38 & 22.71 & 1.12 & 20.25 & 1.48 & 20.62 \\
\hline $\mathrm{Bel}^{1}$ & 0.60 & 20.84 & 20.90 & 1.06 & 21.30 & 0.69 & 22.02 & 1.21 & 22.54 & 0.64 & 19.78 & 1.10 & 20.24 \\
\hline Baronesa & -0.39 & 19.84 & 19.80 & 0.55 & 20.79 & 0.07 & 21.40 & 0.77 & 22.09 & -0.94 & 18.20 & 0.44 & 19.58 \\
\hline Eliza $^{3}$ & -0.97 & 19.27 & 19.16 & 0.37 & 20.60 & -0.80 & 20.53 & 0.53 & 21.86 & -1.34 & 17.80 & 0.18 & 19.31 \\
\hline Asterix & -1.16 & 19.08 & 18.95 & 0.30 & 20.53 & -1.57 & 19.76 & 0.36 & 21.69 & -0.98 & 18.15 & 0.38 & 19.51 \\
\hline
\end{tabular}

Regarding the characters glucose content (Table 8), greening (Table 9), cracking (Table 10), secondary growth (Table 11) and sprouting (Table 12), the families ranked higher are those with lower genetic values. Since, to obtain light frying color and to prevent the formation of acrylamide, low glucose is required (Wang et al., 2016). For better industrial use of the tubers it is desirable low percentages of cracking, secondary growth, greening and sprouting. In addition, glycalokaloids are synthesized in green tubers together with chlorophyll (Grunenfelder et al., 2006), which are toxic to the central nervous system and gastrointestinal system.

Thus, regarding the glucose content character, considering the average interaction of the environments $(\mathrm{u}+\mathrm{g}+\mathrm{gem})$, the families 11 (BRSIPR Bel x Ludmilla) and 20 (Markies x C1883-22-97) present the lowest values: $0.11 \mathrm{mg} \mathrm{g}^{-1}$ of DM. In spring growing, these same families had the lowest genetic values $(\mathrm{g})$, while in summer growing family 11 descended two positions in the rank. The cultivar BRSIPR Bel had glucose values very close to zero for both growing periods, so that calculations for genotypic values were not performed, as expected, since this cultivar is suitable for frying. The cultivar BRS Eliza presented the highest genotypic value in spring and summer growing, and the Baronesa cultivar had the third highest genotypic value in summer, which was also expected because the reducing sugar content of these cultivars is high and medium-high, respectively. 
Table 8. Genetic values $(\mathrm{g})$, predicted genotypic values $(\mathrm{u}+\mathrm{g})$, average genotypic value $(\mathrm{u}+\mathrm{g}+\mathrm{gem})$, gains, new average with selection (N Average), evaluation of 20 potato families and 6 control cultivars, for the character glucose content, in the spring 2017 and summer 2017/2018 crops in Pelotas-RS. Embrapa,

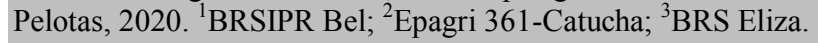

\begin{tabular}{|c|c|c|c|c|c|c|c|c|c|c|c|c|c|}
\hline \multirow{2}{*}{ Genotypes } & \multicolumn{5}{|c|}{ General } & \multicolumn{4}{|c|}{ Spring } & \multicolumn{4}{|c|}{ Summer } \\
\hline & g & $\mathbf{u}+\mathbf{g}$ & u+g+gem & Gain & N Average & g & $\mathbf{u}+\mathbf{g}$ & Gain & N Average & g & $\mathbf{u}+\mathbf{g}$ & Gain & N Average \\
\hline 20 & -0.09 & 0.12 & 0.11 & 0.00 & 0.21 & -0.10 & 0.11 & 0.00 & 0.21 & -0.10 & 0.12 & 0.00 & 0.22 \\
\hline 11 & -0.09 & 0.12 & 0.11 & 0.00 & 0.21 & -0.10 & 0.11 & 0.00 & 0.20 & -0.09 & 0.12 & 0.01 & 0.23 \\
\hline 12 & -0.09 & 0.12 & 0.12 & 0.01 & 0.22 & -0.10 & 0.11 & 0.01 & 0.21 & -0.09 & 0.12 & 0.02 & 0.24 \\
\hline 35 & -0.09 & 0.12 & 0.12 & 0.01 & 0.22 & -0.09 & 0.11 & 0.01 & 0.22 & -0.10 & 0.12 & 0.00 & 0.22 \\
\hline 8 & -0.08 & 0.13 & 0.12 & 0.02 & 0.23 & -0.08 & 0.12 & 0.02 & 0.22 & -0.10 & 0.12 & 0.01 & 0.23 \\
\hline 37 & -0.07 & 0.14 & 0.13 & 0.02 & 0.23 & -0.07 & 0.13 & 0.03 & 0.24 & -0.08 & 0.14 & 0.02 & 0.24 \\
\hline 18 & -0.07 & 0.14 & 0.14 & 0.03 & 0.24 & -0.08 & 0.12 & 0.02 & 0.23 & -0.07 & 0.15 & 0.04 & 0.25 \\
\hline 13 & -0.06 & 0.15 & 0.15 & 0.03 & 0.24 & -0.07 & 0.13 & 0.03 & 0.23 & -0.05 & 0.16 & 0.05 & 0.27 \\
\hline 19 & -0.05 & 0.16 & 0.16 & 0.04 & 0.25 & -0.03 & 0.17 & 0.07 & 0.27 & -0.07 & 0.14 & 0.03 & 0.25 \\
\hline 5 & -0.04 & 0.17 & 0.17 & 0.05 & 0.26 & -0.04 & 0.16 & 0.05 & 0.25 & -0.04 & 0.18 & 0.06 & 0.28 \\
\hline 21 & -0.04 & 0.17 & 0.17 & 0.06 & 0.27 & -0.03 & 0.17 & 0.08 & 0.29 & -0.05 & 0.17 & 0.05 & 0.27 \\
\hline 2 & -0.03 & 0.18 & 0.18 & 0.06 & 0.27 & -0.05 & 0.16 & 0.05 & 0.25 & -0.02 & 0.20 & 0.07 & 0.29 \\
\hline 7 & -0.02 & 0.19 & 0.19 & 0.07 & 0.28 & -0.04 & 0.17 & 0.06 & 0.26 & 0.00 & 0.22 & 0.09 & 0.31 \\
\hline 34 & -0.01 & 0.20 & 0.20 & 0.08 & 0.29 & -0.03 & 0.17 & 0.08 & 0.28 & 0.01 & 0.23 & 0.11 & 0.32 \\
\hline 36 & -0.01 & 0.20 & 0.20 & 0.09 & 0.30 & -0.01 & 0.20 & 0.10 & 0.30 & -0.01 & 0.21 & 0.08 & 0.30 \\
\hline 26 & 0.01 & 0.22 & 0.22 & 0.10 & 0.31 & 0.01 & 0.21 & 0.11 & 0.31 & 0.02 & 0.24 & 0.13 & 0.35 \\
\hline 25 & 0.03 & 0.24 & 0.25 & 0.14 & 0.35 & 0.06 & 0.26 & 0.17 & 0.37 & 0.02 & 0.23 & 0.12 & 0.34 \\
\hline 16 & 0.08 & 0.29 & 0.29 & 0.18 & 0.39 & 0.07 & 0.27 & 0.20 & 0.40 & 0.09 & 0.31 & 0.18 & 0.39 \\
\hline 17 & 0.13 & 0.34 & 0.35 & 0.22 & 0.43 & 0.16 & 0.36 & 0.24 & 0.44 & 0.11 & 0.33 & 0.20 & 0.41 \\
\hline 27 & 0.23 & 0.44 & 0.46 & 0.26 & 0.47 & 0.25 & 0.45 & 0.28 & 0.48 & 0.25 & 0.47 & 0.28 & 0.50 \\
\hline Atlantic & $\begin{array}{l}-0.06 \\
\end{array}$ & 0.15 & 0.15 & 0.04 & 0.25 & $\begin{array}{l}-0.06 \\
\end{array}$ & 0.14 & 0.04 & 0.24 & -0.07 & 0.15 & 0.04 & 0.26 \\
\hline Catucha $^{2}$ & 0.02 & 0.23 & 0.23 & 0.11 & 0.32 & 0.04 & 0.24 & 0.12 & 0.32 & 0.00 & 0.22 & 0.09 & 0.30 \\
\hline Asterix & 0.03 & 0.24 & 0.24 & 0.12 & 0.33 & 0.05 & 0.25 & 0.15 & 0.35 & 0.02 & 0.24 & 0.15 & 0.37 \\
\hline Baronesa & 0.07 & 0.28 & 0.29 & 0.16 & 0.37 & 0.04 & 0.24 & 0.13 & 0.33 & 0.12 & 0.34 & 0.22 & 0.44 \\
\hline Eliza $^{3}$ & 0.29 & 0.50 & 0.52 & 0.29 & 0.50 & 0.31 & 0.51 & 0.31 & 0.51 & 0.31 & 0.52 & 0.31 & 0.52 \\
\hline $\mathrm{Bel}^{1}$ & & & & & & & & & & & & & \\
\hline
\end{tabular}

Table 9. Genetic values $(\mathrm{g})$, predicted genotypic values $(\mathrm{u}+\mathrm{g})$, average genotypic value $(\mathrm{u}+\mathrm{g}+\mathrm{gem})$, gains, new average with selection (N Average), evaluation of 20 potato families and 6 control cultivars, for the character tuber greening, in the spring 2017 and summer 2017/2018 crops in Pelotas-RS. Embrapa,

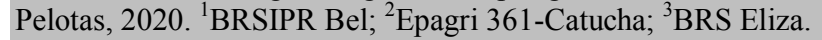

\begin{tabular}{|c|c|c|c|c|c|c|c|c|c|c|c|c|c|}
\hline \multirow{2}{*}{ Genotypes } & \multicolumn{5}{|c|}{ General } & \multicolumn{4}{|c|}{ Spring } & \multicolumn{4}{|c|}{ Summer } \\
\hline & $\mathrm{g}$ & $\mathbf{u}+\mathbf{g}$ & $\mathbf{u}+\mathbf{g}+\mathbf{g e m}$ & Gain & N Average & g & $u+g$ & Gain & N Average & g & $\mathbf{u}+\mathbf{g}$ & Gain & N Average \\
\hline 20 & -0.08 & 2.58 & 1.83 & 0.00 & 2.66 & -1.61 & 2.17 & 0.08 & 3.87 & -0.06 & 1.48 & 0.46 & 2.00 \\
\hline 11 & -0.07 & 2.59 & 1.87 & 0.00 & 2.66 & -1.15 & 2.64 & 0.16 & 3.94 & -0.43 & 1.11 & 0.03 & 1.56 \\
\hline 17 & -0.06 & 2.60 & 2.00 & 0.01 & 2.67 & -0.90 & 2.89 & 0.29 & 4.07 & -0.42 & 1.12 & 0.05 & 1.59 \\
\hline 16 & -0.06 & 2.60 & 2.06 & 0.01 & 2.67 & -1.14 & 2.64 & 0.22 & 4.00 & & & & \\
\hline 25 & -0.05 & 2.61 & 2.15 & 0.01 & 2.67 & -0.81 & 2.97 & 0.49 & 4.27 & -0.21 & 1.33 & 0.22 & 1.75 \\
\hline 5 & -0.05 & 2.61 & 2.16 & 0.02 & 2.68 & -1.91 & 1.87 & 0.00 & 3.78 & 0.91 & 2.45 & 1.12 & 2.65 \\
\hline 26 & -0.04 & 2.62 & 2.21 & 0.02 & 2.68 & -0.83 & 2.96 & 0.35 & 4.13 & -0.07 & 1.46 & 0.40 & 1.93 \\
\hline 27 & -0.04 & 2.62 & 2.28 & 0.03 & 2.69 & -0.17 & 3.61 & 0.70 & 4.49 & -0.60 & 0.94 & 0.00 & 1.53 \\
\hline 37 & -0.03 & 2.63 & 2.38 & 0.03 & 2.69 & -0.16 & 3.62 & 0.77 & 4.55 & -0.39 & 1.14 & 0.08 & 1.62 \\
\hline 19 & -0.02 & 2.64 & 2.44 & 0.03 & 2.69 & -0.49 & 3.29 & 0.57 & 4.35 & 0.05 & 1.58 & 0.66 & 2.20 \\
\hline 2 & -0.02 & 2.64 & 2.45 & 0.04 & 2.70 & -0.07 & 3.72 & 0.93 & 4.72 & -0.36 & 1.18 & 0.12 & 1.65 \\
\hline 7 & -0.02 & 2.64 & 2.49 & 0.04 & 2.70 & -0.24 & 3.54 & 0.64 & 4.42 & -0.10 & 1.43 & 0.30 & 1.83 \\
\hline 34 & 0.00 & 2.66 & 2.62 & 0.05 & 2.71 & -0.07 & 3.71 & 0.85 & 4.63 & & . & & 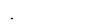 \\
\hline 8 & 0.00 & 2.66 & 2.66 & 0.05 & 2.71 & 0.21 & 3.99 & 1.13 & 4.92 & -0.20 & 1.33 & 0.25 & 1.79 \\
\hline 13 & 0.01 & 2.67 & 2.74 & 0.06 & 2.72 & 0.24 & 4.03 & 1.40 & 5.18 & -0.09 & 1.45 & 0.34 & 1.88 \\
\hline 21 & 0.01 & 2.67 & 2.75 & 0.06 & 2.72 & 0.42 & 4.21 & 1.59 & 5.37 & -0.25 & 1.28 & 0.15 & 1.69 \\
\hline 12 & 0.01 & 2.67 & 2.76 & 0.07 & 2.73 & 0.22 & 4.00 & 1.25 & 5.03 & -0.01 & 1.52 & 0.55 & 2.09 \\
\hline 18 & 0.03 & 2.69 & 3.01 & 0.09 & 2.75 & 0.94 & 4.72 & 2.61 & 6.39 & -0.23 & 1.31 & 0.18 & 1.72 \\
\hline 36 & 0.04 & 2.70 & 3.06 & 0.10 & 2.76 & 0.11 & 3.89 & 1.03 & 4.82 & 0.70 & 2.23 & 0.98 & 2.51 \\
\hline 35 & 0.07 & 2.73 & 3.35 & 0.14 & 2.80 & . & . & & & 1.32 & 2.86 & 1.32 & 2.86 \\
\hline Asterix & -0.04 & 2.62 & 2.23 & 0.02 & 2.68 & $\begin{array}{l}-0.82 \\
\end{array}$ & 2.97 & 0.42 & 4.20 & & . & & . \\
\hline Catucha $^{2}$ & 0.03 & 2.69 & 2.93 & 0.08 & 2.74 & 0.52 & 4.30 & 1.82 & 5.61 & & . & . & . \\
\hline Eliza $^{3}$ & 0.04 & 2.70 & 3.06 & 0.11 & 2.77 & 0.77 & 4.55 & 2.15 & 5.93 & . & . & . & . \\
\hline Atlantic & 0.12 & 2.79 & 3.98 & 0.17 & 2.83 & 2.52 & 6.30 & 3.44 & 7.23 & & & & \\
\hline $\mathrm{Bel}^{1}$ & 0.22 & 2.88 & 5.02 & 0.22 & 2.88 & 4.37 & 8.16 & 4.37 & 8.16 & 0.35 & 1.89 & 0.82 & 2.36 \\
\hline Baronesa & & & & & & & & & & & & & \\
\hline
\end{tabular}


Table 10. Genetic values $(\mathrm{g})$, predicted genotypic values $(\mathrm{u}+\mathrm{g})$, average genotypic value $(\mathrm{u}+\mathrm{g}+\mathrm{gem})$, gains, new average with selection (N Average), evaluation of 20 potato families and 6 control cultivars, for the character tuber cracking, in the spring 2017 and summer 2017/2018 crops in Pelotas-RS. Embrapa, Pelotas, 2020. ${ }^{1}$ BRSIPR Bel; ${ }^{2}$ Epagri $361-$ Catucha; ${ }^{3}$ BRS Eliza.

\begin{tabular}{|c|c|c|c|c|c|c|c|c|c|c|c|c|c|}
\hline \multirow{2}{*}{ Genotypes } & \multicolumn{5}{|c|}{ General } & \multicolumn{4}{|c|}{ Spring } & \multicolumn{4}{|c|}{ Summer } \\
\hline & g & $\mathbf{u}+\mathbf{g}$ & $\mathbf{u}+\mathrm{g}+\mathrm{gem}$ & Gain & N Average & $\mathrm{g}$ & $\mathbf{u}+\mathbf{g}$ & Gain & N Average & g & $\mathbf{u}+\mathbf{g}$ & Gain & N Average \\
\hline 26 & -0.69 & 2.22 & 1.84 & 0.00 & 2.91 & -1.45 & 2.10 & 0.08 & 3.62 & & & & \\
\hline 37 & -0.68 & 2.23 & 1.85 & 0.03 & 2.94 & -1.25 & 2.29 & 0.29 & 3.84 & -0.86 & 1.41 & 0.08 & 2.36 \\
\hline 11 & -0.67 & 2.24 & 1.87 & 0.06 & 2.97 & -1.57 & 1.98 & 0.01 & 3.56 & -0.50 & 1.77 & 0.22 & 2.50 \\
\hline 8 & -0.66 & 2.25 & 1.88 & 0.09 & 3.01 & -1.13 & 2.42 & 0.46 & 4.01 & -0.93 & 1.35 & 0.03 & 2.31 \\
\hline 27 & -0.61 & 2.31 & 1.97 & 0.13 & 3.04 & -1.28 & 2.27 & 0.22 & 3.77 & . & . & . & . \\
\hline 5 & -0.57 & 2.34 & 2.02 & 0.17 & 3.08 & -1.21 & 2.34 & 0.37 & 3.92 & & & & \\
\hline 20 & -0.42 & 2.49 & 2.25 & 0.20 & 3.12 & -1.35 & 2.20 & 0.15 & 3.69 & 0.03 & 2.31 & 0.85 & 3.13 \\
\hline 34 & -0.33 & 2.58 & 2.40 & 0.24 & 3.15 & -0.70 & 2.85 & 0.55 & 4.10 & & & & \\
\hline 36 & -0.30 & 2.61 & 2.45 & 0.27 & 3.19 & -0.34 & 3.21 & 0.63 & 4.18 & -0.58 & 1.69 & 0.13 & 2.41 \\
\hline 12 & -0.28 & 2.63 & 2.48 & 0.31 & 3.22 & -0.34 & 3.21 & 0.70 & 4.25 & -0.53 & 1.74 & 0.17 & 2.45 \\
\hline 18 & -0.25 & 2.66 & 2.52 & 0.35 & 3.26 & -0.29 & 3.26 & 0.86 & 4.40 & -0.50 & 1.78 & 0.27 & 2.54 \\
\hline 13 & -0.12 & 2.80 & 2.73 & 0.44 & 3.35 & -0.05 & 3.49 & 0.95 & 4.50 & -0.31 & 1.97 & 0.44 & 2.71 \\
\hline 7 & -0.11 & 2.80 & 2.74 & 0.48 & 3.39 & 0.00 & 3.55 & 1.04 & 4.59 & -0.36 & 1.92 & 0.38 & 2.65 \\
\hline 16 & -0.02 & 2.89 & 2.88 & 0.54 & 3.45 & -0.33 & 3.22 & 0.77 & 4.32 & 0.25 & 2.53 & 1.14 & 3.42 \\
\hline 21 & -0.02 & 2.89 & 2.88 & 0.59 & 3.50 & 0.18 & 3.73 & 1.15 & 4.70 & -0.25 & 2.02 & 0.50 & 2.78 \\
\hline 17 & 0.18 & 3.09 & 3.20 & 0.66 & 3.57 & 0.55 & 4.10 & 1.37 & 4.92 & 0.02 & 2.29 & 0.75 & 3.03 \\
\hline 35 & 0.27 & 3.18 & 3.33 & 0.72 & 3.63 & 0.32 & 3.87 & 1.25 & 4.80 & 0.52 & 2.80 & 1.36 & 3.64 \\
\hline 2 & 0.34 & 3.25 & 3.44 & 0.78 & 3.70 & 1.08 & 4.63 & 1.94 & 5.49 & -0.03 & 2.25 & 0.66 & 2.94 \\
\hline 19 & 0.38 & 3.30 & 3.51 & 0.86 & 3.77 & 1.36 & 4.91 & 2.23 & 5.77 & -0.17 & 2.11 & 0.58 & 2.86 \\
\hline 25 & 0.76 & 3.68 & 4.10 & 1.09 & 4.00 & 0.66 & 4.21 & 1.49 & 5.04 & 1.71 & 3.99 & 1.92 & 4.19 \\
\hline Asterix & -0.18 & 2.73 & 2.63 & 0.39 & 3.30 & & & & & -0.39 & 1.89 & 0.32 & 2.60 \\
\hline $\mathrm{Bel}^{1}$ & 0.39 & 3.30 & 3.52 & 0.95 & 3.86 & 0.97 & 4.52 & 1.63 & 5.17 & 0.24 & 2.52 & 0.99 & 3.27 \\
\hline Atlantic & 0.97 & 3.88 & 4.41 & 1.20 & 4.11 & 1.90 & 5.45 & 2.66 & 6.21 & 1.09 & 3.37 & 1.64 & 3.92 \\
\hline Baronesa & 1.01 & 3.93 & 4.49 & 1.32 & 4.23 & 1.03 & 4.58 & 1.76 & 5.31 & 2.12 & 4.40 & 2.12 & 4.40 \\
\hline Eliza $^{3}$ & 1.62 & 4.54 & 5.43 & 1.62 & 4.54 & 3.42 & 6.96 & 3.42 & 6.96 & & . & & . \\
\hline Catucha ${ }^{2}$ & . & & & 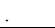 & & & 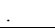 & 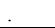 & 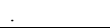 & & . & & . \\
\hline
\end{tabular}

Table 11. Genetic values $(\mathrm{g})$, predicted genotypic values $(\mathrm{u}+\mathrm{g})$, average genotypic value $(\mathrm{u}+\mathrm{g}+\mathrm{gem})$, gains, new average with selection (N Average), evaluation of 20 potato families and 6 control cultivars, for the character tuber secondary growth, in the spring 2017 and summer 2017/2018 crops in Pelotas-RS. Embrapa, Pelotas, 2020. ${ }^{1}$ BRSIPR Bel; ${ }^{2}$ Epagri 361-Catucha; ${ }^{3}$ BRS Eliza.

\begin{tabular}{|c|c|c|c|c|c|c|c|c|c|c|c|c|c|}
\hline \multirow{2}{*}{ Genotypes } & \multicolumn{5}{|c|}{ General } & \multicolumn{4}{|c|}{ Spring } & \multicolumn{4}{|c|}{ Summer } \\
\hline & $\mathrm{g}$ & $\mathbf{u}+\mathrm{g}$ & u+g+gem & Gain & N Average & $\mathrm{g}$ & $u+g$ & Gain & N Average & $\mathrm{g}$ & $\mathbf{u}+\mathbf{g}$ & Gain & N Average \\
\hline 12 & -4.22 & 0.71 & 0.67 & 0.00 & 4.93 & . & . & . & . & -4.31 & 3.50 & 0.00 & 7.81 \\
\hline 11 & -3.90 & 1.03 & 0.99 & 0.17 & 5.10 & . & . & . & . & -3.98 & 3.83 & 0.17 & 7.99 \\
\hline 37 & -2.59 & 2.35 & 2.32 & 0.34 & 5.27 & . & . & . & . & -2.64 & 5.17 & 0.35 & 8.16 \\
\hline 21 & -2.27 & 2.67 & 2.64 & 0.47 & 5.40 & -2.24 & -0.19 & 0.43 & 2.48 & -2.34 & 5.47 & 0.48 & 8.29 \\
\hline 34 & -1.60 & 3.34 & 3.32 & 0.59 & 5.52 & -1.58 & 0.48 & 0.57 & 2.62 & -1.65 & 6.16 & 0.71 & 8.52 \\
\hline 8 & -1.59 & 3.34 & 3.32 & 0.69 & 5.63 & -1.56 & 0.50 & 0.69 & 2.74 & -1.66 & 6.15 & 0.60 & 8.42 \\
\hline 17 & -0.95 & 3.98 & 3.97 & 1.03 & 5.96 & -0.95 & 1.10 & 0.94 & 3.00 & -0.98 & 6.84 & 1.05 & 8.87 \\
\hline 5 & -0.45 & 4.48 & 4.48 & 1.27 & 6.21 & -0.47 & 1.59 & 1.21 & 3.26 & -0.45 & 7.37 & 1.31 & 9.12 \\
\hline 13 & -0.16 & 4.77 & 4.77 & 1.39 & 6.32 & -0.17 & 1.89 & 1.34 & 3.39 & -0.17 & 7.65 & 1.42 & 9.24 \\
\hline 18 & -0.07 & 4.87 & 4.87 & 1.50 & 6.43 & -0.09 & 1.97 & 1.46 & 3.52 & -0.05 & 7.77 & 1.66 & 9.47 \\
\hline 7 & -0.02 & 4.92 & 4.92 & 1.62 & 6.55 & 0.04 & 2.10 & 1.60 & 3.66 & -0.08 & 7.74 & 1.54 & 9.35 \\
\hline 27 & 0.20 & 5.13 & 5.13 & 1.75 & 6.69 & 0.18 & 2.24 & 1.76 & 3.81 & 0.22 & 8.03 & 1.80 & 9.62 \\
\hline 20 & 0.37 & 5.31 & 5.31 & 1.90 & 6.83 & 0.32 & 2.37 & 1.93 & 3.99 & 0.44 & 8.25 & 1.95 & 9.76 \\
\hline 16 & 0.65 & 5.58 & 5.59 & 2.05 & 6.98 & 0.62 & 2.68 & 2.14 & 4.19 & 0.69 & 8.50 & 2.10 & 9.91 \\
\hline 26 & 0.80 & 5.73 & 5.74 & 2.20 & 7.14 & 0.79 & 2.84 & 2.35 & 4.41 & 0.82 & 8.63 & 2.26 & 10.07 \\
\hline 36 & 1.04 & 5.98 & 5.99 & 2.38 & 7.31 & 1.05 & 3.11 & 2.61 & 4.67 & 1.05 & 8.87 & 2.43 & 10.25 \\
\hline 19 & 1.43 & 6.36 & 6.38 & 2.57 & 7.51 & 1.39 & 3.45 & 2.92 & 4.98 & 1.50 & 9.31 & 2.63 & 10.44 \\
\hline 2 & 1.61 & 6.54 & 6.56 & 3.01 & 7.95 & 1.56 & 3.61 & 3.31 & 5.36 & 1.70 & 9.51 & 3.08 & 10.89 \\
\hline 35 & 1.71 & 6.65 & 6.67 & 3.37 & 8.30 & 1.71 & 3.76 & 3.89 & 5.95 & 1.75 & 9.57 & 3.42 & 11.24 \\
\hline 25 & 3.74 & 8.68 & 8.71 & 4.96 & 9.90 & 3.78 & 5.84 & 4.98 & 7.04 & 3.78 & 11.59 & 5.04 & 12.86 \\
\hline Atlantic & -1.17 & 3.76 & 3.75 & 0.81 & 5.74 & & & & & -1.20 & 6.61 & 0.94 & 8.75 \\
\hline $\mathrm{Bel}^{1}$ & -1.15 & 3.78 & 3.77 & 0.91 & 5.85 & -1.13 & 0.92 & 0.82 & 2.88 & -1.20 & 6.61 & 0.83 & 8.64 \\
\hline Asterix & -0.90 & 4.03 & 4.02 & 1.14 & 6.08 & -0.88 & 1.18 & 1.07 & 3.12 & -0.95 & 6.87 & 1.17 & 8.99 \\
\hline Baronesa & 1.50 & 6.43 & 6.45 & 2.76 & 7.70 & . & . & . & . & 1.53 & 9.34 & 2.82 & 10.63 \\
\hline Catucha $^{2}$ & 1.82 & 6.76 & 6.77 & 3.92 & 8.85 & 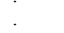 & & & & 1.86 & 9.67 & 3.98 & 11.79 \\
\hline Eliza $^{3}$ & 6.18 & 11.12 & 11.18 & 6.18 & 11.12 & 6.18 & 8.24 & 6.18 & 8.24 & 6.31 & 14.12 & 6.31 & 14.12 \\
\hline
\end{tabular}


Table 12. Genetic values $(\mathrm{g})$, predicted genotypic values $(\mathrm{u}+\mathrm{g})$, average genotypic value $(\mathrm{u}+\mathrm{g}+\mathrm{gem})$, gains, new average with selection (N Average), evaluation of 20 potato families and 6 control cultivars, for the character tuber sprouting, in the spring 2017 and summer 2017/2018 crops in Pelotas-RS. Embrapa, Pelotas, 2020. ${ }^{1}$ BRSIPR Bel; ${ }^{2}$ Epagri $361-C a t u c h a ; ~{ }^{3}$ BRS Eliza.

\begin{tabular}{|c|c|c|c|c|c|c|c|c|c|c|c|c|c|}
\hline \multirow{2}{*}{ Genotypes } & \multicolumn{5}{|c|}{ General } & \multicolumn{4}{|c|}{ Spring } & \multicolumn{4}{|c|}{ Summer } \\
\hline & g & $\mathbf{u}+\mathbf{g}$ & $\mathrm{u}+\mathrm{g}+\mathrm{gem}$ & Gain & N Average & $\mathrm{g}$ & $\mathbf{u}+\mathbf{g}$ & Gain & N Average & $\mathrm{g}$ & $\mathbf{u}+\mathbf{g}$ & Gain & N Average \\
\hline 8 & -0.53 & 6.28 & 3.51 & 0.02 & 6.83 & 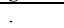 & & . & . & -6.05 & 4.66 & 0.25 & 10.97 \\
\hline 11 & -0.43 & 6.37 & 4.12 & 0.05 & 6.85 & . & . & . & . & -4.94 & 5.78 & 0.53 & 11.24 \\
\hline 37 & -0.42 & 6.39 & 4.20 & 0.07 & 6.87 & . & . & . & . & -4.79 & 5.93 & 0.78 & 11.49 \\
\hline 21 & -0.26 & 6.54 & 5.16 & 0.11 & 6.92 & . & . & . & . & -3.03 & 7.68 & 1.29 & 12.00 \\
\hline 18 & -0.26 & 6.55 & 5.19 & 0.13 & 6.94 & . & . & . & . & -2.98 & 7.74 & 1.51 & 12.23 \\
\hline 27 & -0.24 & 6.57 & 5.33 & 0.15 & 6.96 & . & . & . & . & -2.71 & 8.00 & 1.76 & 12.48 \\
\hline 35 & -0.20 & 6.60 & 5.54 & 0.18 & 6.98 & . & . & . & . & -2.33 & 8.38 & 2.03 & 12.74 \\
\hline 26 & -0.17 & 6.63 & 5.73 & 0.20 & 7.01 & . & . & . & . & -1.98 & 8.74 & 2.30 & 13.01 \\
\hline 12 & -0.17 & 6.64 & 5.76 & 0.23 & 7.03 & . & . & . & . & -1.92 & 8.80 & 2.58 & 13.30 \\
\hline 20 & -0.09 & 6.71 & 6.22 & 0.25 & 7.06 & . & . & . & . & -1.07 & 9.65 & 2.90 & 13.62 \\
\hline 25 & -0.02 & 6.78 & 6.66 & 0.28 & 7.09 & . & . & . & . & -0.28 & 10.44 & 3.21 & 13.93 \\
\hline 36 & 0.00 & 6.80 & 6.79 & 0.31 & 7.11 & & & & . & -0.03 & 10.69 & 3.50 & 14.22 \\
\hline 19 & 0.01 & 6.82 & 6.87 & 0.33 & 7.14 & -0.87 & 0.72 & 0.34 & 1.93 & 1.01 & 11.72 & 4.14 & 14.86 \\
\hline 7 & 0.06 & 6.86 & 7.16 & 0.37 & 7.17 & -0.72 & 0.87 & 0.51 & 2.10 & 1.42 & 12.14 & 4.92 & 15.64 \\
\hline 34 & 0.07 & 6.87 & 7.24 & 0.40 & 7.21 & -0.22 & 1.38 & 0.92 & 2.51 & 1.08 & 11.79 & 4.49 & 15.21 \\
\hline 13 & 0.19 & 7.00 & 7.99 & 0.44 & 7.25 & & & & & 2.18 & 12.90 & 5.42 & 16.14 \\
\hline 17 & 0.41 & 7.22 & 9.37 & 0.58 & 7.38 & 0.77 & 2.36 & 1.62 & 3.21 & 4.36 & 15.07 & 6.66 & 17.38 \\
\hline 5 & 0.44 & 7.24 & 9.54 & 0.62 & 7.42 & -0.04 & 1.55 & 1.20 & 2.79 & 5.50 & 16.21 & 7.24 & 17.96 \\
\hline 2 & 0.56 & 7.37 & 10.31 & 0.68 & 7.48 & & & . & . & 6.44 & 17.16 & 7.82 & 18.54 \\
\hline 16 & 0.65 & 7.45 & 10.82 & 0.73 & 7.54 & -0.29 & 1.30 & 0.72 & 2.31 & 8.33 & 19.04 & 8.51 & 19.23 \\
\hline Asterix & -0.53 & 6.27 & 3.49 & 0.00 & 6.81 & . & . & . & . & -6.10 & 4.62 & 0.00 & 10.72 \\
\hline $\mathrm{Bel}^{1}$ & -0.34 & 6.47 & 4.72 & 0.09 & 6.90 & & 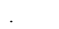 & . & . & -3.84 & 6.87 & 1.04 & 11.76 \\
\hline Baronesa & 0.21 & 7.02 & 8.13 & 0.48 & 7.28 & & & & & 2.44 & 13.15 & 5.96 & 16.68 \\
\hline Eliza $^{3}$ & 0.25 & 7.06 & 8.39 & 0.52 & 7.33 & 2.57 & 4.17 & 2.57 & 4.17 & 0.59 & 11.30 & 3.82 & 14.54 \\
\hline Catucha $^{2}$ & 0.82 & 7.63 & 11.91 & 0.82 & 7.63 & 1.50 & 3.10 & 2.04 & 3.63 & 8.70 & 19.41 & 8.70 & 19.41 \\
\hline Atlantic & & & & . & 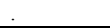 & & & . & . & . & & & \\
\hline
\end{tabular}

Based on these results, it was verified that the growing environment influenced the families' behavior for glucose character, and considering both environments the family 20 had the best performance.

For the greening character the families with the lowest average genotypic value of the two crops $(\mathrm{u}+\mathrm{g}+$ gem) were 20 (Markies x C1883-22-97) and 11 (BRSIPR Bel $\mathrm{x}$ Ludmilla), with values of: 1.83 and $1.87 \%$, respectively. However, distinct behaviors of families regarding genetic values $(\mathrm{g})$ were observed in the different environments evaluated, which was already predicted due to the low genotypic correlation between the performance of the environments (0.05) (Table 2). In spring growing, the family with the lowest genetic value was 5 (C2519-12-06 x 118-1) (-1.91\%), and family 35 (Caesar x C2514-05-06) showed no green tubers. While in summer growing, family 27 (F88-01-05 x Monalisa) had the lowest genetic value (-0.60\%) and families 34 (BRSIPR Bel x Voyager) and 16 (Baronesa x Asterix) showed no green tubers.

Regarding the performance of the cultivars for this character, a distinct behavior among the cultivars was also observed for Atlantic, BRS Eliza and Epagri 361-Catucha, which, in spring growing, obtained high genetic values, but in summer they did not even have green tubers. However, the cultivar BRSIPR Bel was in the rank of four highest genetic values in both crops. Therefore, for the greening character of tubers, the growing environment should be considered when selecting families.

Regarding the cracking of tubers character, the families with the lowest average genotypic values $(\mathrm{u}+\mathrm{g}+$ gem) were 26 (BRSIPR Bel x Monalisa) and 37 (C1730-7-94 x Aracy) with 1.84 and $1.85 \%$, respectively. In spring growing, families 11 (BRSIPR Bel $x$ Ludmilla) (-1.57\%) and 26 (BRSIPR Bel x Monalisa) (-1.45\%) had the lowest genetic 
values. However, under summer growing conditions, families with genetic values $(\mathrm{g})$ below were 8 (BRSIPR Bel x IAC-Ibituaçu) (-0.93\%) and 37 (C1730-7-94 x Aracy) (- 0.86\%), with families 5 (C2519-12-06 x 118-1), 26 (BRSIPR Bel x Monalisa), 27 (F88-01-05 x Monalisa) and 37 (C1730-7-94 x Aracy), showing no tuber cracking during this growing season. This difficulty in selecting families with phenotypic stability for this character was already expected given the low genotypic correlation between environmental performance (0.48) (Table 2).

Distinct behavior between the crops was also observed for the cultivar BRS Eliza, which in spring growing had the highest genetic value $(3.42 \%)$, while in summer the presence of cracked tubers was not verified. Thus, the growing environment should be considered for the selection of families for tuber cracking character.

Regarding the secondary growth of tubers, considering the average interaction of the environments $(\mathrm{u}+\mathrm{g}+\mathrm{gem})$, it can be verified that the families 12 (BRSIPR Bel $\mathrm{x}$ C1883-22-97) and 11 (BRSIPR Bel x Ludmilla) had the lowest values, -4.22 and $-3.90 \%$, respectively. These same families presented the lowest genetic values in spring and summer growing. Therefore, families 11 and 12 may be considered in a selection for the secondary growth of tubers character.

Regarding the tuber sprouting character, it was found that at spring growing families 2 (BRS Ana x C1890-1-97), 8 (BRSIPR Bel x IAC-Ibituaçu), 11 (BRSIPR Bel x Ludmilla), 12 (BRSIPR Bel x C1883-22-97), 13 (BRSIPR Bel x Amorosa), 18 (BRSIPR Bel x Asterix), 20 (Markies x C1883-22-97), 21 (BRSIPR Bel x Markies) and 25 (118.1 x CL07-05) showed no sprouting. Most of these families presented the lowest genetic values in summer growing, as in the case of families $8(-6.05 \%), 11(-4.94 \%)$ and $37(-4.79 \%)$. Similarly, the cultivars that did not sprout in spring growing had the lowest genetic values in summer growing. While the cultivar Atlantic had similar behavior in both crops.

For the characters external appearance components of tubers it can be said that the growing environments did not interfere in the ranking of the families, since the upper family in the spring remained superior in the summer, except for the format uniformity character.

Regarding the tuber shape (Table 13), considering an ideotype aimed at the production of potato sticks, the shape should be oval-long to elongated (Birch et al., 2012), so indices greater than 151 are preferable. Thus, when considering the average interaction of the environments $(\mathrm{u}+\mathrm{g}+\mathrm{gem})$, which is equivalent to the average genotypic value of the two crops, family 27 (F88-01-05 x Monalisa) had the highest value: 153.76, and if selected the gain will be 14.34 and the new average of 151.50 . This same family obtained higher genetic value (g) in spring (20.03) and summer (13.16) crops. Therefore, for the tuber shape character, family 27 presented greater adaptability among the other families tested in these crops.

For the selection of families regarding the film texture character (Table 14), lower values represent rougher texture, which will promote greater resistance to mechanical damage. Thus, as family 19 obtained the lowest average genotypic value (3.60), if the selection gain was selected, it would be 0.07 , and the new average would be 4.26 . This family was superior in both tested growing environments and can be considered in a selection aiming at resistance to mechanical damage. 
Table 13. Genetic values $(\mathrm{g})$, predicted genotypic values $(\mathrm{u}+\mathrm{g})$, average genotypic value $(\mathrm{u}+\mathrm{g}+\mathrm{gem})$, gains, new average with selection (N Average), evaluation of 20 potato families and 6 control cultivars, for the character tuber shape, in the spring 2017 and summer 2017/2018 crops in Pelotas-RS. Embrapa,

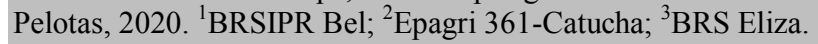

\begin{tabular}{|c|c|c|c|c|c|c|c|c|c|c|c|c|c|}
\hline \multirow{2}{*}{ Genotypes } & \multicolumn{5}{|l|}{ General } & \multicolumn{4}{|l|}{ Spring } & \multicolumn{4}{|c|}{ Summer } \\
\hline & g & $\mathbf{u}+\mathrm{g}$ & $\mathbf{u}+\mathrm{g}+\mathrm{gem}$ & Gain & N Average & g & $\mathbf{u}+\mathbf{g}$ & Gain & N Average & g & $\mathbf{u}+\mathbf{g}$ & Gain & N Average \\
\hline 27 & 14.34 & 151.50 & 153.76 & 14.34 & 151.50 & 20.03 & 159.94 & 20.03 & 159.94 & 13.16 & 147.57 & 13.16 & 147.57 \\
\hline 35 & 11.69 & 148.85 & 150.69 & 13.01 & 150.17 & 15.18 & 155.10 & 17.23 & 157.14 & 11.87 & 146.29 & 12.55 & 146.97 \\
\hline 25 & 11.30 & 148.46 & 150.24 & 12.44 & 149.60 & 13.53 & 153.44 & 16.08 & 155.99 & 12.62 & 147.04 & 12.89 & 147.30 \\
\hline 17 & 9.64 & 146.80 & 148.32 & 11.34 & 148.50 & 15.74 & 155.66 & 17.91 & 157.82 & 6.57 & 140.98 & 9.72 & 144.13 \\
\hline 16 & 7.60 & 144.76 & 145.96 & 10.80 & 147.96 & 9.60 & 149.51 & 15.27 & 155.18 & 7.99 & 142.41 & 10.97 & 145.38 \\
\hline 11 & 3.44 & 140.60 & 141.15 & 9.55 & 146.71 & 2.91 & 142.82 & 12.80 & 152.72 & 5.06 & 139.47 & 8.84 & 143.25 \\
\hline 26 & 2.50 & 139.66 & 140.06 & 8.84 & 146.01 & 2.99 & 142.91 & 13.90 & 153.82 & 2.79 & 137.21 & 7.38 & 141.79 \\
\hline 5 & 0.49 & 137.65 & 137.73 & 7.55 & 144.72 & -1.92 & 137.99 & 9.80 & 149.71 & 3.05 & 137.47 & 7.80 & 142.21 \\
\hline 2 & 0.02 & 137.18 & 137.19 & 6.97 & 144.14 & -3.11 & 136.80 & 8.11 & 148.03 & 3.15 & 137.57 & 8.27 & 142.68 \\
\hline 19 & -0.02 & 137.14 & 137.14 & 6.47 & 143.64 & 2.35 & 142.26 & 11.85 & 151.77 & -2.39 & 132.02 & 5.25 & 139.66 \\
\hline 18 & -1.03 & 136.13 & 135.97 & 5.97 & 143.14 & -1.05 & 138.86 & 10.78 & 150.69 & -1.33 & 133.08 & 6.30 & 140.71 \\
\hline 13 & -3.19 & 133.98 & 133.47 & 5.40 & 142.56 & -5.60 & 134.32 & 6.52 & 146.43 & -1.78 & 132.63 & 5.76 & 140.17 \\
\hline 7 & -3.62 & 133.54 & 132.97 & 4.87 & 142.03 & -5.28 & 134.64 & 7.27 & 147.19 & -3.10 & 131.31 & 4.34 & 138.75 \\
\hline 34 & -3.64 & 133.52 & 132.95 & 4.40 & 141.56 & -5.65 & 134.27 & 5.84 & 145.76 & -2.78 & 131.63 & 4.78 & 139.19 \\
\hline 21 & -5.17 & 132.00 & 131.18 & 3.89 & 141.06 & -6.58 & 133.33 & 5.19 & 145.10 & -5.38 & 129.03 & 3.05 & 137.47 \\
\hline 36 & -6.04 & 131.12 & 130.17 & 2.95 & 140.11 & -8.73 & 131.18 & 3.89 & 143.80 & -5.25 & 129.16 & 3.48 & 137.89 \\
\hline 20 & -7.48 & 129.68 & 128.50 & 2.47 & 139.64 & -8.16 & 131.75 & 4.52 & 144.43 & -9.16 & 125.25 & 2.14 & 136.55 \\
\hline 8 & -8.84 & 128.32 & 126.92 & 1.98 & 139.15 & -14.70 & 125.21 & 1.84 & 141.76 & -5.77 & 128.64 & 2.65 & 137.06 \\
\hline 12 & -10.96 & 126.20 & 124.47 & 1.44 & 138.61 & -12.15 & 127.76 & 2.56 & 142.48 & -13.23 & 121.18 & 0.93 & 135.34 \\
\hline 37 & -12.59 & 124.57 & 122.59 & 0.88 & 138.04 & -16.32 & 123.60 & 1.12 & 141.03 & -12.83 & 121.58 & 1.52 & 135.93 \\
\hline Catucha $^{2}$ & 10.55 & 147.71 & 149.38 & 11.97 & 149.13 & 17.95 & 157.87 & 18.99 & 158.90 & 6.47 & 140.88 & 9.31 & 143.72 \\
\hline Baronesa & 10.51 & 147.67 & 149.32 & 11.68 & 148.84 & 15.12 & 155.03 & 16.80 & 156.72 & 9.21 & 143.62 & 11.72 & 146.13 \\
\hline Asterix & 6.89 & 144.06 & 145.14 & 10.31 & 147.48 & 14.99 & 154.90 & 16.50 & 156.42 & 0.97 & 135.38 & 6.89 & 141.30 \\
\hline Eliza $^{3}$ & 1.71 & 138.87 & 139.14 & 8.20 & 145.36 & -2.63 & 137.28 & 8.91 & 148.83 & 6.58 & 141.00 & 10.24 & 144.65 \\
\hline $\mathrm{Bel}^{1}$ & -6.04 & 131.12 & 130.17 & 3.40 & 140.56 & -10.61 & 129.30 & 3.23 & 143.14 & -3.37 & 131.04 & 3.94 & 138.35 \\
\hline Atlantic & -22.04 & 115.12 & 111.65 & 0.00 & 137.16 & -27.89 & 112.03 & 0.00 & 139.91 & -23.14 & 111.27 & 0.00 & 134.41 \\
\hline
\end{tabular}

Table 14. Genetic values $(\mathrm{g})$, predicted genotypic values $(\mathrm{u}+\mathrm{g})$, average genotypic value $(\mathrm{u}+\mathrm{g}+\mathrm{gem})$, gains, new average with selection (N Average), evaluation of 20 potato families and 6 control cultivars, for the character film texture, in the spring 2017 and summer 2017/2018 crops in Pelotas-RS. Embrapa,

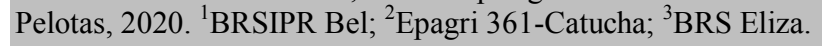

\begin{tabular}{|c|c|c|c|c|c|c|c|c|c|c|c|c|c|}
\hline \multirow{2}{*}{ Genotypes } & \multicolumn{5}{|c|}{ General } & \multicolumn{4}{|c|}{ Spring } & \multicolumn{4}{|c|}{ Summer } \\
\hline & g & $\mathbf{u}+\mathbf{g}$ & $\mathbf{u}+\mathbf{g}+\mathbf{g e m}$ & Gain & N Average & g & $\mathbf{u}+\mathbf{g}$ & Gain & N Average & g & $\mathbf{u}+\mathbf{g}$ & Gain & N Average \\
\hline 27 & 0.79 & 4.98 & 5.02 & 0.79 & 4.98 & 0.79 & 5.61 & 0.79 & 5.61 & 0.86 & 4.43 & 0.86 & 4.43 \\
\hline 13 & 0.59 & 4.78 & 4.81 & 0.67 & 4.86 & 0.55 & 5.37 & 0.68 & 5.50 & 0.68 & 4.24 & 0.77 & 4.34 \\
\hline 26 & 0.57 & 4.77 & 4.80 & 0.65 & 4.84 & 0.60 & 5.42 & 0.72 & 5.54 & 0.61 & 4.18 & 0.70 & 4.27 \\
\hline 36 & 0.52 & 4.71 & 4.74 & 0.62 & 4.82 & 0.52 & 5.34 & 0.65 & 5.47 & 0.58 & 4.15 & 0.68 & 4.24 \\
\hline 25 & 0.48 & 4.67 & 4.70 & 0.60 & 4.79 & 0.35 & 5.17 & 0.55 & 5.37 & 0.66 & 4.22 & 0.73 & 4.30 \\
\hline 8 & 0.33 & 4.52 & 4.54 & 0.56 & 4.75 & 0.42 & 5.24 & 0.61 & 5.43 & 0.27 & 3.83 & 0.51 & 4.08 \\
\hline 37 & 0.25 & 4.45 & 4.46 & 0.50 & 4.69 & 0.21 & 5.03 & 0.51 & 5.33 & 0.32 & 3.88 & 0.57 & 4.14 \\
\hline 21 & 0.22 & 4.41 & 4.43 & 0.47 & 4.66 & 0.15 & 4.97 & 0.45 & 5.27 & 0.32 & 3.88 & 0.61 & 4.18 \\
\hline 34 & 0.07 & 4.26 & 4.27 & 0.41 & 4.60 & 0.11 & 4.93 & 0.42 & 5.24 & 0.04 & 3.60 & 0.41 & 3.97 \\
\hline 20 & 0.05 & 4.24 & 4.24 & 0.38 & 4.57 & 0.07 & 4.89 & 0.39 & 5.21 & 0.03 & 3.60 & 0.36 & 3.92 \\
\hline 18 & 0.03 & 4.22 & 4.22 & 0.35 & 4.55 & 0.03 & 4.85 & 0.37 & 5.19 & 0.03 & 3.60 & 0.38 & 3.95 \\
\hline 12 & 0.03 & 4.22 & 4.22 & 0.33 & 4.53 & -0.02 & 4.80 & 0.34 & 5.16 & 0.08 & 3.64 & 0.47 & 4.04 \\
\hline 17 & -0.07 & 4.12 & 4.12 & 0.31 & 4.50 & -0.04 & 4.78 & 0.32 & 5.14 & -0.11 & 3.46 & 0.31 & 3.87 \\
\hline 5 & -0.13 & 4.06 & 4.05 & 0.28 & 4.47 & -0.23 & 4.59 & 0.26 & 5.08 & -0.05 & 3.52 & 0.33 & 3.90 \\
\hline 16 & -0.23 & 3.96 & 3.95 & 0.25 & 4.45 & -0.33 & 4.49 & 0.20 & 5.02 & -0.16 & 3.41 & 0.28 & 3.85 \\
\hline 11 & -0.25 & 3.94 & 3.93 & 0.23 & 4.42 & -0.31 & 4.51 & 0.23 & 5.05 & -0.22 & 3.35 & 0.25 & 3.82 \\
\hline 35 & -0.26 & 3.93 & 3.92 & 0.20 & 4.39 & -0.20 & 4.63 & 0.29 & 5.11 & -0.36 & 3.21 & 0.22 & 3.79 \\
\hline 7 & -0.40 & 3.79 & 3.77 & 0.17 & 4.37 & -0.42 & 4.40 & 0.15 & 4.97 & -0.43 & 3.14 & 0.19 & 3.76 \\
\hline 2 & -0.48 & 3.72 & 3.69 & 0.09 & 4.29 & -0.52 & 4.30 & 0.09 & 4.91 & -0.48 & 3.08 & 0.16 & 3.73 \\
\hline 19 & -0.56 & 3.63 & 3.60 & 0.07 & 4.26 & -0.63 & 4.19 & 0.07 & 4.89 & -0.56 & 3.01 & 0.10 & 3.67 \\
\hline $\mathrm{Bel}^{1}$ & 0.64 & 4.83 & 4.87 & 0.71 & 4.91 & 0.77 & 5.59 & 0.78 & 5.60 & 0.58 & 4.14 & 0.66 & 4.23 \\
\hline Eliza $^{3}$ & 0.32 & 4.51 & 4.53 & 0.53 & 4.72 & 0.39 & 5.21 & 0.58 & 5.40 & 0.28 & 3.84 & 0.54 & 4.11 \\
\hline Baronesa & 0.09 & 4.29 & 4.29 & 0.44 & 4.63 & 0.15 & 4.97 & 0.48 & 5.30 & 0.04 & 3.61 & 0.44 & 4.01 \\
\hline Catucha $^{2}$ & -0.43 & 3.76 & 3.74 & 0.14 & 4.34 & -0.36 & 4.46 & 0.17 & 4.99 & -0.55 & 3.01 & 0.13 & 3.70 \\
\hline Asterix & -0.47 & 3.72 & 3.70 & 0.12 & 4.31 & -0.42 & 4.40 & 0.12 & 4.94 & -0.57 & 3.00 & 0.07 & 3.64 \\
\hline Atlantic & -1.67 & 2.52 & 2.44 & 0.00 & 4.19 & -1.64 & 3.18 & 0.00 & 4.82 & -1.87 & 1.70 & 0.00 & 3.57 \\
\hline
\end{tabular}


Table 15. Genetic values $(\mathrm{g})$, predicted genotypic values $(\mathrm{u}+\mathrm{g})$, average genotypic value $(\mathrm{u}+\mathrm{g}+\mathrm{gem})$, gains, new average with selection (N Average), evaluation of 20 potato families and 6 control cultivars, for the character tuber shape uniformity, in the spring 2017 and summer 2017/2018 crops in Pelotas-RS. Embrapa, Pelotas, 2020. ${ }^{1}$ BRSIPR Bel; ${ }^{2}$ Epagri 361 -Catucha; ${ }^{3}$ BRS Eliza.

\begin{tabular}{|c|c|c|c|c|c|c|c|c|c|c|c|c|c|}
\hline \multirow{2}{*}{ Genotypes } & \multicolumn{5}{|c|}{ General } & \multicolumn{4}{|c|}{ Spring } & \multicolumn{4}{|c|}{ Summer } \\
\hline & g & $\mathbf{u}+\mathbf{g}$ & $\mathbf{u}+\mathbf{g}+\mathrm{gem}$ & Gain & N Average & $\mathrm{g}$ & $\mathbf{u}+\mathbf{g}$ & Gain & N Average & g & $\mathbf{u}+\mathbf{g}$ & Gain & N Average \\
\hline 11 & 0.29 & 6.19 & 6.30 & 0.86 & 6.76 & 0.28 & 6.78 & 0.70 & 7.20 & 0.53 & 5.82 & 1.06 & 6.35 \\
\hline 12 & 0.28 & 6.17 & 6.28 & 0.72 & 6.61 & 0.08 & 6.58 & 0.54 & 7.04 & 0.69 & 5.98 & 1.51 & 6.80 \\
\hline 37 & 0.26 & 6.16 & 6.26 & 0.63 & 6.52 & 0.08 & 6.58 & 0.48 & 6.98 & 0.65 & 5.94 & 1.30 & 6.58 \\
\hline 17 & 0.14 & 6.03 & 6.08 & 0.55 & 6.44 & 0.19 & 6.69 & 0.61 & 7.11 & 0.19 & 5.47 & 0.78 & 6.06 \\
\hline 34 & 0.09 & 5.98 & 6.02 & 0.48 & 6.38 & 0.05 & 6.55 & 0.43 & 6.93 & 0.20 & 5.49 & 0.85 & 6.14 \\
\hline 8 & 0.08 & 5.98 & 6.01 & 0.43 & 6.33 & 0.00 & 6.50 & 0.31 & 6.81 & 0.23 & 5.52 & 0.94 & 6.23 \\
\hline 20 & 0.06 & 5.95 & 5.98 & 0.33 & 6.23 & -0.01 & 6.49 & 0.26 & 6.76 & 0.17 & 5.46 & 0.72 & 6.00 \\
\hline 35 & 0.02 & 5.91 & 5.92 & 0.31 & 6.20 & 0.04 & 6.54 & 0.39 & 6.89 & 0.01 & 5.30 & 0.61 & 5.90 \\
\hline 2 & 0.02 & 5.91 & 5.92 & 0.28 & 6.18 & 0.04 & 6.54 & 0.36 & 6.86 & 0.01 & 5.30 & 0.57 & 5.85 \\
\hline 18 & -0.01 & 5.88 & 5.88 & 0.26 & 6.16 & 0.03 & 6.53 & 0.33 & 6.83 & -0.06 & 5.23 & 0.52 & 5.81 \\
\hline 21 & -0.01 & 5.88 & 5.88 & 0.24 & 6.14 & -0.20 & 6.30 & 0.18 & 6.68 & 0.17 & 5.45 & 0.67 & 5.95 \\
\hline 13 & -0.10 & 5.80 & 5.76 & 0.22 & 6.12 & -0.10 & 6.40 & 0.22 & 6.72 & -0.17 & 5.12 & 0.40 & 5.69 \\
\hline 27 & -0.15 & 5.74 & 5.68 & 0.20 & 6.10 & -0.01 & 6.49 & 0.28 & 6.78 & -0.42 & 4.87 & 0.35 & 5.64 \\
\hline 19 & -0.22 & 5.68 & 5.59 & 0.18 & 6.07 & -0.45 & 6.05 & 0.10 & 6.60 & -0.15 & 5.14 & 0.48 & 5.76 \\
\hline 26 & -0.25 & 5.65 & 5.55 & 0.15 & 6.05 & -0.22 & 6.28 & 0.16 & 6.66 & -0.47 & 4.82 & 0.31 & 5.60 \\
\hline 25 & -0.33 & 5.57 & 5.44 & 0.11 & 6.01 & -0.31 & 6.19 & 0.14 & 6.64 & -0.59 & 4.69 & 0.27 & 5.55 \\
\hline 36 & -0.34 & 5.55 & 5.42 & 0.09 & 5.99 & -0.32 & 6.19 & 0.12 & 6.62 & -0.63 & 4.66 & 0.22 & 5.51 \\
\hline 5 & -0.35 & 5.54 & 5.41 & 0.07 & 5.97 & -0.06 & 6.44 & 0.24 & 6.74 & -0.91 & 4.38 & 0.09 & 5.38 \\
\hline 16 & -0.35 & 5.54 & 5.41 & 0.05 & 5.95 & -0.12 & 6.38 & 0.20 & 6.71 & -0.85 & 4.44 & 0.13 & 5.42 \\
\hline 7 & -0.50 & 5.39 & 5.20 & 0.03 & 5.93 & -0.63 & 5.87 & 0.04 & 6.54 & -0.75 & 4.54 & 0.18 & 5.47 \\
\hline Atlantic & 1.25 & 7.14 & 7.62 & 1.25 & 7.14 & 1.41 & 7.91 & 1.41 & 7.91 & 2.04 & 7.32 & 2.04 & 7.32 \\
\hline $\mathrm{Bel}^{1}$ & 1.05 & 6.95 & 7.35 & 1.15 & 7.04 & 1.10 & 7.60 & 1.25 & 7.76 & 1.80 & 7.09 & 1.92 & 7.21 \\
\hline Baronesa & 0.08 & 5.97 & 6.00 & 0.39 & 6.29 & 0.38 & 6.88 & 0.96 & 7.46 & -0.16 & 5.13 & 0.44 & 5.72 \\
\hline Catucha $^{2}$ & 0.07 & 5.96 & 5.99 & 0.36 & 6.25 & -0.46 & 6.04 & 0.07 & 6.57 & 0.65 & 5.94 & 1.17 & 6.45 \\
\hline Asterix & -0.27 & 5.63 & 5.52 & 0.13 & 6.03 & 0.31 & 6.81 & 0.80 & 7.30 & -1.05 & 4.24 & 0.04 & 5.33 \\
\hline Eliza $^{3}$ & -0.80 & 5.09 & 4.79 & 0.00 & 5.89 & -1.09 & 5.41 & 0.00 & 6.50 & -1.12 & 4.17 & 0.00 & 5.29 \\
\hline
\end{tabular}

Table 16. Genetic values $(\mathrm{g})$, predicted genotypic values $(\mathrm{u}+\mathrm{g})$, average genotypic value $(\mathrm{u}+\mathrm{g}+\mathrm{gem})$, gains, new average with selection (N Average), evaluation of 20 potato families and 6 control cultivars, for the character tuber size uniformity, in the spring 2017 and summer 2017/2018 crops in Pelotas-RS.

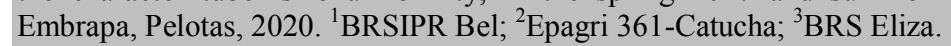

\begin{tabular}{|c|c|c|c|c|c|c|c|c|c|c|c|c|c|}
\hline \multirow{2}{*}{ Genotypes } & \multicolumn{5}{|c|}{ General } & \multicolumn{4}{|c|}{ Spring } & \multicolumn{4}{|c|}{ Summer } \\
\hline & g & $\mathbf{u}+\mathbf{g}$ & u+g+gem & Gain & N Average & g & $\mathbf{u}+\mathbf{g}$ & Gain & N Average & g & $\mathbf{u}+\mathbf{g}$ & Gain & N Average \\
\hline 11 & 0.52 & 6.15 & 6.31 & 0.82 & 6.45 & 0.56 & 6.85 & 0.97 & 7.26 & 0.80 & 5.77 & 1.33 & 6.30 \\
\hline 13 & 0.33 & 5.96 & 6.06 & 0.72 & 6.35 & 0.15 & 6.45 & 0.64 & 6.94 & 0.70 & 5.66 & 1.09 & 6.05 \\
\hline 21 & 0.16 & 5.79 & 5.84 & 0.53 & 6.16 & 0.19 & 6.48 & 0.72 & 7.02 & 0.22 & 5.19 & 0.73 & 5.69 \\
\hline 12 & 0.08 & 5.71 & 5.74 & 0.48 & 6.11 & -0.02 & 6.28 & 0.42 & 6.72 & 0.23 & 5.19 & 0.79 & 5.75 \\
\hline 35 & 0.05 & 5.68 & 5.69 & 0.44 & 6.07 & -0.19 & 6.11 & 0.24 & 6.53 & 0.31 & 5.28 & 0.86 & 5.82 \\
\hline 8 & -0.03 & 5.60 & 5.59 & 0.39 & 6.02 & 0.04 & 6.34 & 0.46 & 6.76 & -0.12 & 4.85 & 0.59 & 5.55 \\
\hline 17 & -0.11 & 5.52 & 5.48 & 0.35 & 5.98 & -0.18 & 6.11 & 0.30 & 6.59 & -0.11 & 4.85 & 0.65 & 5.62 \\
\hline 26 & -0.14 & 5.49 & 5.45 & 0.31 & 5.94 & -0.21 & 6.09 & 0.21 & 6.50 & -0.15 & 4.81 & 0.53 & 5.50 \\
\hline 34 & -0.15 & 5.48 & 5.44 & 0.28 & 5.91 & -0.16 & 6.13 & 0.33 & 6.63 & -0.22 & 4.74 & 0.40 & 5.36 \\
\hline 37 & -0.17 & 5.46 & 5.40 & 0.25 & 5.88 & -0.27 & 6.03 & 0.16 & 6.45 & -0.18 & 4.78 & 0.44 & 5.40 \\
\hline 19 & -0.18 & 5.45 & 5.39 & 0.22 & 5.85 & -0.14 & 6.15 & 0.37 & 6.67 & -0.33 & 4.63 & 0.32 & 5.28 \\
\hline 2 & -0.21 & 5.42 & 5.36 & 0.20 & 5.83 & -0.18 & 6.11 & 0.26 & 6.56 & -0.35 & 4.61 & 0.28 & 5.25 \\
\hline 25 & -0.23 & 5.40 & 5.33 & 0.18 & 5.80 & -0.43 & 5.86 & 0.07 & 6.36 & -0.17 & 4.79 & 0.48 & 5.45 \\
\hline 20 & -0.25 & 5.38 & 5.31 & 0.15 & 5.78 & -0.36 & 5.94 & 0.11 & 6.41 & -0.29 & 4.67 & 0.36 & 5.32 \\
\hline 27 & -0.27 & 5.36 & 5.27 & 0.13 & 5.76 & -0.32 & 5.98 & 0.14 & 6.43 & -0.40 & 4.57 & 0.25 & 5.21 \\
\hline 36 & -0.29 & 5.34 & 5.25 & 0.11 & 5.74 & -0.26 & 6.03 & 0.18 & 6.48 & -0.50 & 4.47 & 0.21 & 5.18 \\
\hline 5 & -0.39 & 5.24 & 5.12 & 0.09 & 5.72 & -0.49 & 5.81 & 0.02 & 6.32 & -0.53 & 4.43 & 0.18 & 5.14 \\
\hline 18 & -0.44 & 5.19 & 5.05 & 0.07 & 5.70 & -0.57 & 5.72 & 0.00 & 6.29 & -0.58 & 4.38 & 0.15 & 5.11 \\
\hline 16 & -0.49 & 5.14 & 4.99 & 0.02 & 5.65 & -0.38 & 5.91 & 0.09 & 6.38 & -0.91 & 4.06 & 0.10 & 5.07 \\
\hline 7 & -0.56 & 5.07 & 4.90 & 0.00 & 5.63 & -0.49 & 5.81 & 0.04 & 6.34 & -0.98 & 3.99 & 0.06 & 5.02 \\
\hline Atlantic & 1.22 & 6.85 & 7.23 & 1.22 & 6.85 & 1.29 & 7.59 & 1.29 & 7.59 & 1.90 & 6.86 & 1.90 & 6.86 \\
\hline $\mathrm{Bel}^{1}$ & 0.88 & 6.51 & 6.78 & 1.05 & 6.68 & 1.01 & 7.30 & 1.15 & 7.44 & 1.30 & 6.26 & 1.60 & 6.56 \\
\hline Baronesa & 0.67 & 6.30 & 6.50 & 0.92 & 6.55 & 1.01 & 7.30 & 1.10 & 7.40 & 0.74 & 5.71 & 1.19 & 6.15 \\
\hline Eliza $^{3}$ & 0.25 & 5.88 & 5.96 & 0.65 & 6.27 & 0.06 & 6.36 & 0.57 & 6.86 & 0.59 & 5.56 & 1.01 & 5.97 \\
\hline Catucha ${ }^{2}$ & 0.21 & 5.84 & 5.90 & 0.58 & 6.21 & 0.05 & 6.34 & 0.51 & 6.81 & 0.50 & 5.46 & 0.93 & 5.90 \\
\hline Asterix & -0.45 & 5.18 & 5.04 & 0.04 & 5.67 & 0.29 & 6.58 & 0.83 & 7.12 & -1.47 & 3.50 & 0.00 & 4.96 \\
\hline
\end{tabular}

Genetics and Molecular Research 19 (4): gmr18597 
Regarding the tuber curvature character (Table 17), the smaller the curvature, the greater will be the industrial yield of the tuber. Note that grade 1 refers to steep curvature and grade 9 to no curvature, so higher values are preferable. Thus, family 19 (C1750-15-95 $\mathrm{x}$ Asterix) obtained the highest average genotypic value: 6.17 , as well as the highest genetic values both in spring (0.19) as well as in summer $(0.20)$, and could be considered in a selection for low tuber curvature.

Table 17. Genetic values $(\mathrm{g})$, predicted genotypic values $(\mathrm{u}+\mathrm{g})$, average genotypic value $(\mathrm{u}+\mathrm{g}+\mathrm{gem})$, gains, new average with selection (N Average), evaluation of 20 potato families and 6 control cultivars, for the character tuber curvature, in the spring 2017 and summer 2017/2018 crops in Pelotas-RS. Embrapa, Pelotas, 2020. ${ }^{1}$ BRSIPR Bel; ${ }^{2}$ Epagri $361-$ Catucha; ${ }^{3}$ BRS Eliza.

\begin{tabular}{|c|c|c|c|c|c|c|c|c|c|c|c|c|c|}
\hline \multirow{2}{*}{ Genotypes } & \multicolumn{5}{|c|}{ General } & \multicolumn{4}{|c|}{ Spring } & \multicolumn{4}{|c|}{ Summer } \\
\hline & g & $\mathbf{u}+\mathbf{g}$ & $\mathbf{u}+\mathbf{g}+\mathrm{gem}$ & Gain & N Average & g & $\mathbf{u}+\mathbf{g}$ & Gain & N Average & g & $\mathbf{u}+\mathbf{g}$ & Gain & N Average \\
\hline 19 & 0.19 & 6.17 & 6.17 & 0.48 & 6.45 & 0.19 & 6.68 & 0.47 & 6.97 & 0.20 & 5.66 & 0.49 & 5.95 \\
\hline 21 & 0.09 & 6.06 & 6.06 & 0.41 & 6.39 & 0.08 & 6.58 & 0.41 & 6.91 & 0.09 & 5.55 & 0.42 & 5.88 \\
\hline 18 & 0.03 & 6.01 & 6.01 & 0.36 & 6.34 & 0.04 & 6.54 & 0.35 & 6.85 & 0.03 & 5.49 & 0.32 & 5.78 \\
\hline 7 & 0.03 & 6.01 & 6.01 & 0.32 & 6.29 & 0.03 & 6.53 & 0.31 & 6.81 & 0.03 & 5.49 & 0.37 & 5.82 \\
\hline 12 & 0.02 & 6.00 & 6.00 & 0.26 & 6.24 & 0.02 & 6.52 & 0.26 & 6.76 & 0.03 & 5.48 & 0.29 & 5.75 \\
\hline 20 & 0.00 & 5.98 & 5.98 & 0.23 & 6.21 & -0.01 & 6.49 & 0.23 & 6.73 & 0.00 & 5.46 & 0.24 & 5.70 \\
\hline 37 & -0.01 & 5.97 & 5.97 & 0.21 & 6.19 & -0.01 & 6.49 & 0.21 & 6.71 & -0.01 & 5.44 & 0.20 & 5.66 \\
\hline 34 & -0.01 & 5.97 & 5.97 & 0.20 & 6.18 & -0.01 & 6.49 & 0.20 & 6.70 & -0.01 & 5.44 & 0.19 & 5.64 \\
\hline 26 & -0.01 & 5.97 & 5.97 & 0.18 & 6.16 & -0.01 & 6.49 & 0.18 & 6.68 & -0.01 & 5.45 & 0.22 & 5.68 \\
\hline 11 & -0.03 & 5.95 & 5.95 & 0.17 & 6.15 & -0.03 & 6.47 & 0.17 & 6.67 & -0.03 & 5.43 & 0.17 & 5.63 \\
\hline 8 & -0.06 & 5.92 & 5.92 & 0.15 & 6.13 & -0.05 & 6.45 & 0.15 & 6.65 & -0.06 & 5.40 & 0.16 & 5.61 \\
\hline 16 & -0.06 & 5.91 & 5.91 & 0.14 & 6.12 & -0.07 & 6.43 & 0.14 & 6.64 & -0.06 & 5.40 & 0.14 & 5.60 \\
\hline 36 & -0.09 & 5.89 & 5.89 & 0.13 & 6.11 & -0.09 & 6.41 & 0.13 & 6.63 & -0.10 & 5.36 & 0.13 & 5.59 \\
\hline 13 & -0.12 & 5.86 & 5.86 & 0.12 & 6.09 & -0.11 & 6.39 & 0.12 & 6.61 & -0.12 & 5.34 & 0.12 & 5.58 \\
\hline 5 & -0.16 & 5.82 & 5.82 & 0.10 & 6.08 & -0.16 & 6.34 & 0.10 & 6.60 & -0.16 & 5.30 & 0.10 & 5.56 \\
\hline 2 & -0.18 & 5.80 & 5.80 & 0.09 & 6.07 & -0.17 & 6.33 & 0.09 & 6.59 & -0.19 & 5.27 & 0.09 & 5.55 \\
\hline 17 & -0.26 & 5.72 & 5.72 & 0.06 & 6.04 & -0.26 & 6.24 & 0.06 & 6.56 & -0.26 & 5.20 & 0.07 & 5.53 \\
\hline 35 & -0.30 & 5.68 & 5.67 & 0.04 & 6.02 & -0.30 & 6.20 & 0.04 & 6.54 & -0.31 & 5.15 & 0.04 & 5.50 \\
\hline 25 & -0.36 & 5.62 & 5.61 & 0.03 & 6.01 & -0.36 & 6.14 & 0.03 & 6.53 & -0.37 & 5.09 & 0.03 & 5.49 \\
\hline 27 & -0.68 & 5.30 & 5.29 & 0.00 & 5.98 & -0.68 & 5.82 & 0.00 & 6.50 & -0.69 & 4.77 & 0.00 & 5.46 \\
\hline $\mathrm{Bel}^{1}$ & 1.02 & 7.00 & 7.01 & 1.02 & 7.00 & 1.02 & 7.52 & 1.02 & 7.52 & 1.05 & 6.51 & 1.05 & 6.51 \\
\hline Asterix & 0.45 & 6.43 & 6.44 & 0.74 & 6.72 & 0.45 & 6.95 & 0.74 & 7.24 & 0.46 & 5.92 & 0.76 & 6.21 \\
\hline Atlantic & 0.43 & 6.41 & 6.42 & 0.64 & 6.61 & 0.43 & 6.93 & 0.63 & 7.13 & 0.45 & 5.90 & 0.65 & 6.11 \\
\hline Catucha $^{2}$ & 0.28 & 6.26 & 6.26 & 0.55 & 6.53 & 0.28 & 6.78 & 0.54 & 7.04 & 0.28 & 5.74 & 0.56 & 6.02 \\
\hline Baronesa & 0.03 & 6.00 & 6.01 & 0.28 & 6.26 & 0.03 & 6.53 & 0.28 & 6.78 & 0.02 & 5.48 & 0.26 & 5.72 \\
\hline Eliza $^{3}$ & $\begin{array}{l}0.25 \\
-0.25\end{array}$ & $\begin{array}{l}5.00 \\
5.73\end{array}$ & 5.73 & 0.07 & 6.05 & $\begin{array}{r}-0.24 \\
-0.24\end{array}$ & 6.26 & 0.07 & 6.57 & -0.26 & 5.20 & 0.06 & 5.52 \\
\hline
\end{tabular}

Tuber shape uniformity (Table 15) was higher for family 11 (BRSIPR Bel $\mathrm{x}$ Ludmilla) by checking the mean genotypic effect $(\mathrm{u}+\mathrm{g}+$ gem $)$ : 6.30 . In spring growing this family had the greatest genetic effect: 0.28 . However, in summer it fell two places in the rank (0.53) and families 12 (BRSIPR Bel x C1883-22-97) and 37 (C1730-7-94 x Aracy) obtained the highest genetic values: 0.69 and 0.65 , respectively, demonstrating that the growing environment affects the behavior of these families regarding the uniformity of tuber shape.

Family 11 also had the highest average genotypic effect for size uniformity (Table 16) (6.31) and the highest genetic effect in both spring (0.56) and summer (0.80) growings. This same family obtained higher average genotypic value in relation to the tuber general appearance character (5.20) as well as higher genetic value in both growing environments. Thus, for the characters size uniformity and general appearance of tubers (Table 18), family 11 stood out from the other families. 
Table 18. Genetic values $(\mathrm{g})$, predicted genotypic values $(\mathrm{u}+\mathrm{g})$, average genotypic value $(\mathrm{u}+\mathrm{g}+\mathrm{gem})$, gains, new average with selection (N Average), evaluation of 20 potato families and 6 control cultivars, for the character tuber general appearance, in the spring 2017 and summer 2017/2018 crops in Pelotas-RS. Embrapa, Pelotas, 2020. ${ }^{1}$ BRSIPR Bel; ${ }^{2}$ Epagri 361-Catucha; ${ }^{3}$ BRS Eliza.

\begin{tabular}{|c|c|c|c|c|c|c|c|c|c|c|c|c|c|}
\hline \multirow{2}{*}{ Genotypes } & \multicolumn{5}{|c|}{ General } & \multicolumn{4}{|c|}{ Spring } & \multicolumn{4}{|c|}{ Summer } \\
\hline & g & $\mathbf{u}+\mathbf{g}$ & $\mathbf{u}+\mathbf{g}+\mathrm{gem}$ & Gain & N Average & g & $\mathbf{u}+\mathbf{g}$ & Gain & N Average & g & $\mathbf{u}+\mathbf{g}$ & Gain & N Average \\
\hline 11 & 0.86 & 4.98 & 5.20 & 1.55 & 5.66 & 0.63 & 5.37 & 1.86 & 6.60 & 1.54 & 5.03 & 2.51 & 6.00 \\
\hline 8 & 0.24 & 4.36 & 4.42 & 1.20 & 5.32 & 0.12 & 4.86 & 1.41 & 6.15 & 0.49 & 3.98 & 1.71 & 5.20 \\
\hline 12 & 0.23 & 4.35 & 4.41 & 1.06 & 5.18 & -0.43 & 4.31 & 0.60 & 5.34 & 1.01 & 4.50 & 1.96 & 5.45 \\
\hline 21 & 0.17 & 4.28 & 4.33 & 0.95 & 5.07 & -0.01 & 4.73 & 1.00 & 5.74 & 0.43 & 3.92 & 1.53 & 5.02 \\
\hline 36 & 0.13 & 4.25 & 4.28 & 0.86 & 4.98 & 0.46 & 5.20 & 1.63 & 6.37 & -0.14 & 3.35 & 0.98 & 4.47 \\
\hline 37 & 0.04 & 4.16 & 4.17 & 0.78 & 4.89 & 0.06 & 4.80 & 1.12 & 5.86 & 0.05 & 3.55 & 1.22 & 4.71 \\
\hline 26 & -0.09 & 4.03 & 4.01 & 0.70 & 4.82 & 0.11 & 4.85 & 1.25 & 5.99 & -0.33 & 3.17 & 0.79 & 4.28 \\
\hline 34 & -0.10 & 4.02 & 3.99 & 0.63 & 4.75 & -0.47 & 4.28 & 0.53 & 5.27 & 0.22 & 3.71 & 1.36 & 4.86 \\
\hline 13 & -0.13 & 3.98 & 3.95 & 0.57 & 4.69 & -0.16 & 4.58 & 0.74 & 5.48 & -0.18 & 3.31 & 0.88 & 4.38 \\
\hline 17 & -0.19 & 3.93 & 3.88 & 0.52 & 4.64 & -0.13 & 4.61 & 0.82 & 5.56 & -0.35 & 3.14 & 0.71 & 4.20 \\
\hline 18 & -0.28 & 3.84 & 3.77 & 0.47 & 4.58 & -0.25 & 4.49 & 0.67 & 5.41 & -0.45 & 3.05 & 0.57 & 4.06 \\
\hline 20 & -0.29 & 3.82 & 3.75 & 0.42 & 4.54 & -0.68 & 4.06 & 0.35 & 5.09 & -0.06 & 3.43 & 1.09 & 4.58 \\
\hline 2 & -0.43 & 3.69 & 3.58 & 0.33 & 4.44 & -0.71 & 4.03 & 0.30 & 5.04 & -0.36 & 3.13 & 0.64 & 4.13 \\
\hline 27 & -0.50 & 3.62 & 3.49 & 0.28 & 4.40 & -0.59 & 4.15 & 0.41 & 5.15 & -0.67 & 2.82 & 0.38 & 3.88 \\
\hline 5 & -0.54 & 3.58 & 3.44 & 0.24 & 4.36 & -0.56 & 4.18 & 0.47 & 5.21 & -0.80 & 2.70 & 0.27 & 3.77 \\
\hline 35 & -0.58 & 3.54 & 3.39 & 0.20 & 4.32 & -0.74 & 4.00 & 0.25 & 4.99 & -0.71 & 2.79 & 0.33 & 3.82 \\
\hline 7 & -0.72 & 3.40 & 3.21 & 0.16 & 4.28 & -0.85 & 3.89 & 0.20 & 4.94 & -0.95 & 2.54 & 0.17 & 3.67 \\
\hline 19 & -0.74 & 3.37 & 3.18 & 0.12 & 4.24 & -1.25 & 3.49 & 0.00 & 4.74 & -0.63 & 2.87 & 0.44 & 3.93 \\
\hline 25 & -0.89 & 3.23 & 3.00 & 0.08 & 4.20 & -1.24 & 3.50 & 0.05 & 4.79 & -0.99 & 2.50 & 0.12 & 3.62 \\
\hline 16 & -1.00 & 3.12 & 2.86 & 0.00 & 4.12 & -0.91 & 3.83 & 0.15 & 4.89 & -1.60 & 1.89 & 0.00 & 3.49 \\
\hline Atlantic & 2.07 & 6.19 & 6.72 & 2.07 & 6.19 & 2.22 & 6.96 & 2.36 & 7.11 & 3.00 & 6.49 & 3.00 & 6.49 \\
\hline $\mathrm{Bel}^{1}$ & 2.02 & 6.14 & 6.66 & 2.05 & 6.16 & 2.11 & 6.85 & 2.28 & 7.02 & 2.99 & 6.48 & 2.99 & 6.48 \\
\hline Catucha $^{2}$ & 1.23 & 5.34 & 5.66 & 1.77 & 5.89 & 1.84 & 6.58 & 2.17 & 6.91 & 1.25 & 4.74 & 2.19 & $\begin{array}{l}0.70 \\
5.69\end{array}$ \\
\hline Baronesa & 0.78 & 4.90 & 5.10 & 1.39 & 5.51 & 2.51 & 7.25 & 2.51 & 7.25 & -0.54 & 2.95 & 0.50 & 4.00 \\
\hline Asterix & -0.39 & 3.73 & 3.63 & 0.37 & 4.49 & -0.11 & 4.63 & 0.90 & 5.64 & -0.86 & 2.63 & 0.22 & 3.72 \\
\hline Eliza $^{3}$ & -0.92 & 3.20 & 2.96 & 0.04 & 4.16 & -0.95 & 3.79 & 0.10 & 4.84 & -1.37 & 2.13 & 0.06 & 3.56 \\
\hline
\end{tabular}

\section{CONCLUSIONS}

From the study of a hybrid potato population with complementary processing and genetically distant traits, conducted in two distinct growing environments, it was concluded that: heritability.

- Film texture and glucose content showed high estimates of broad sense

- Percentage of commercial tuber mass, mean tuber mass, dry matter content, secondary growth, shape, curvature, shape uniformity, size uniformity and overall appearance of tubers showed moderate estimates of broad sense heritability.

- Total tuber mass, commercial tuber mass, cracking, greening and sprouting of tubers present low estimates of broad sense heritability.

- Glucose content, shape, texture and overall appearance of tubers may be subjected to higher selection pressure.

- The greatest gains with selection are obtained with families 8 (BRSIPR Bel $\mathrm{x}$ IAC-Ibituaçu) for total tuber mass, dry mass content and sprouting; 20 (Markies x C188322-97) for percentage of commercial tuber mass and glucose content; 36 (BRSIPR Bel x Cupido) for mean tuber mass; 27 (F88-01-05 x Monalisa) for tuber shape; 19 (C1750-15-95 $\mathrm{x}$ Asterix) for tuber curvature and film texture; 11 (BRSIPR Bel x Ludmilla) for secondary growth, shape uniformity, size uniformity and overall appearance of tubers; and 11 (BRSIPR Bel x Ludmilla) and 12 (BRSIPR Bel x C1883-22-97) for secondary tuber growth. 


\title{
ACKNOWLEDGMENTS
}

The authors acknowledge the support team of the potato breeding program of Embrapa Clima Temperado; the fellow students and professors of the Phytotechnics Department of the Faculty of Agronomy 'Eliseu Maciel'; the Coordination for the Improvement of Higher Education Personnel (CAPES), the National Council for Scientific and Technological Development (CNPq), and the Research Support Foundation of the State of Rio Grande do Sul (FAPERGS) for scholarships.

\section{CONFLICTS OF INTEREST}

\author{
The authors declare no conflict of interest.
}

\section{REFERENCES}

AOAC - Association of Official Analytical Chemists (1995). Official methods of analysis of AOAC International. 16th edn. Association of Official Analytical Chemists, Arlington.

Bastos IT, Barbosa MHP, Resende MDV, Peternelli LA, et al. (2007). Avaliação da interação genótipo $\times$ ambiente em cana-de-açúcar via modelos mistos. Pesq. Agropec. Trop. 37: 195-203.

Birch PRJ, Bryan G, Fenton B, Gilroy EM, et al. (2012). Crops that feed the world 8: Potato: Are the trends of increased global production sustainable? Food Secur. 4: 477-508.

Bisognin DA, Rigão MH, Lopes SJ and Storck L (2012). Heritability and correlation among potato tuber traits. Crop Breed. Appl. Biotechnol. 12: 215-219.

Bradshaw JE, Bryan GJ and Ramsay G (2006). Genetic resources (including wild and cultivated Solanum species) and progress in their utilisation in potato breeding. Potato Res. 49: 49-65.

Carvalho IR, Nardino M, Demari GH, Pelegrin AJ, et al. (2017). Components of variance and inter-relation of important traits for maize (Zea mays) breeding. Aust. J. Crop Sci. 11: 982-988.

Dale MFB and Bradshaw JE (2003). Progress in improving processing attributes in potato. Trends Plant Sci. 8: 310-312.

EMBRAPA - Empresa Brasileira de Pesquisa Agropecuária (2019). Laboratório de Agrometeorologia. Available at [http://agromet.cpact.embrapa.br].

Falconer DS (1987). Introdução a genética quantitativa. 1st edn. UFV, Viçosa.

Grunenfelder L, Hiller LK and Knowles NR (2006). Color indices for the assessment of chlorophyll development and greening of fresh market potatoes. Postharvest Biol. Technol. 40: 73-81.

Hayes RJ and Thill CA (2003). Genetic gain from early generation selection for cold chipping genotypes in potato. Plant Breed. 122: 158-163.

Herman DJ, Knowles LO and Knowles NR (2016). Heat stress affects carbohydrate metabolism during cold-induced sweetening of potato (Solanum tuberosum L.). Planta. 245: 563-582.

Hijmans RJ (2003). The effect of climate change on global potato production. Amer. J. Potato Res. 80: 271-279.

Howard HW (1978). The production of new varieties. In: The potato crop: The scientific basis for improvement. (Harris PM, ed.). Chapman \& Hall, London.

Levy D, Kastenbaum E and Itzhak Y (1991). Evaluation of parents and selection for heat tolerance in the early generations of a potato (Solanum tuberosum L.) breeding program. Theor. Appl. Genet 82: 130-136.

Love SL, Werner BK and Pavek JJ (1997). Selection for individual traits in the early generations of a potato breeding program dedicated to producing cultivars with tubers having long shape and russet skin. Am. Potato J. 74: 199-213.

Menezes CB, Pinto CABP and Lambert ES (2001). Combining ability of potato genotypes for cool and warm seasons in Brazil. Crop. Breed. Appl. Biotechnol. 1: 145-157.

Müller DR, Bisognin DA, Andriolo JL, Morin Junior GR, et al. (2009). Expressão dos caracteres e seleção de clones de batata nas condições de cultivo de primavera e outono. Cienc. Rural. 39: 1327-1334.

Nitithamyong A, Vonelbe JH, Wheeler RM and Tibbitts TW (1999). Glycoalkaloids in potato tubers grown under controlled environments. Amer. J. Potato Res. 76: 337-343.

Pereira A da S and Silva GO (2019). Batata: Evolução na oferta de cultivares brasileiras e na produção de tubérculossemente. Seed News. 23: 36-39.

Pereira AS, Silva GO and Castro CM (2016). Melhoramento de batata. In: Melhoramento de hortaliças (Nick C, Borem A, eds). Editora UFV, Viçosa.

Pinto CA, Teixeira AL, Neder DG, Araújo RR, et al. (2010). Potencial de clones elite de batata como novas cultivares para Minas Gerais. Hortic. Bras. 28: 399-405.

Genetics and Molecular Research 19 (4): gmr18597

CFUNPEC-RP www.funpecrp.com.br 
Pupin S, Santos AVA, Zaruma DUG, Miranda AC, et al. (2015). Produtividade, estabilidade e adaptabilidade em progênies de polinização aberta de Eucalyptus urophylla S.T. Blake. Sci. For. 43: 127-134.

Resende MDV (2007). Software Selegen - REML/BLUP: sistema estatístico e seleção genética computadorizada via modelos lineares mistos. 1st edn. Embrapa Florestas, Colombo.

Resende MDV and Duarte JB (2007). Precisão e controle de qualidade em experimentos de avaliação de cultivares. Pesq. Agropec. Trop. 37: 182-194.

Rykaczewska K (2013). The impact of high temperature during growing season on potato cultivars with different response to environmental stresses. Am. J. Plant Sci. 4: 2386-2393.

Salamoni AT, Pereira ADS, Viégas J, Campos AD, et al. (2000). Variância genética de açúcares redutores e matéria seca e suas correlações com características agronômicas em batata. Pesq. Agropec. Bras. 35: 1441-1445.

Silva GO, Carvalho ADF, Souza ZS, Ponijaleki RS, et al. (2016). Desempenho genotípico de clones de batata via modelos mistos. Agrária 11: 259-266.

Silva GO, Ney VG, Pereira AS and Terres LR (2014). Relações entre caracteres de tubérculo de batata nas primeiras gerações de seleção. Rev. Ceres 61: 370-376.

Silva TA (2019). Melhoramento genético de batata para processamento na forma de palitos pré-fritos. Doctoral thesis. Universidade Federal de Pelotas, Pelotas. Available at [http://repositorio.ufpel.edu.br:8080/handle/prefix/4949].

Simon GA, Pinto CABP and Benites FRG (2009). Seleção de famílias clonais de batata em diferentes ambientes. Cienc. Agrotec. 33: 164-169.

Slater AT, Cogan NOI, Hayes BJ, Schultz L, et al. (2014). Improving breeding efficiency in potato using molecular and quantitative genetics. Theor. Appl. Genet. 127: 2279-2292.

Souza VQ, Pereira AS, Silva GO, Neto RF, et al. (2007). Consistency of two stability analysis methods in potatoes. Cienc. Rural. 37: 656-661.

Stark JC, Olsen N, Kleinkopf GE and Love SL (2003). Tuber Quality. In: Potato production systems (Stark JC, Love SL eds). University of Idaho, Aberdeen.

Sun N, Rosen CJ and Thompson AL (2018). Acrylamide formation in processed potatoes as affected by cultivar, nitrogen fertilization and storage time. Amer. J. Potato Res. 95: 473-486.

Temmerman L, Wolf J, Colls J, Bindi M, et al. (2002). Effect of climatic conditions on tuber yield (Solanum tuberosum L.) in the European "CHIP" experiments. Eur. J. Agron. 17: 243-255.

Töfoli JG, Melo PCT, Domingues RJ and Ferrari JT (2013). Controle da requeima e pinta preta da batata por fungicidas: conceitos, evolução e uso integrado. Biológico. 75: 41-52.

Wang Y, Bethke PC, Bussan AJ, Glynn MT, et al. (2016). Acrylamide-forming potential and agronomic properties of elite US potato germplasm from the national fry processing trial. Crop Sci. 56: 30-39.

Zommick DH, Knowles LO, Pavek MJ and Knowles NR (2014). In-season heat stress compromises postharvest quality and low-temperature sweetening resistance in potato (Solanum tuberosum L.). Planta. 239: 1243-1263.

Zorzella CA, Vendruscolo JLS, Treptow RO and Almeida TL (2003). Caracterização física, química e sensorial de genótipos de batata processados na forma de chips. Brazilian J. Food Technol. 6: 15-24. 